\title{
PROPOSICIÓN DE ESTILOS PARA EL ARTE RUPESTRE DEL VALLE DE PUTAENDO, CURSO SUPERIOR DEL RÍO ACONCAGUA
}

\author{
STYLISTIC PROPOSITIONS FOR PUTAENDO VALLEY ROCK ART, \\ UPPER COURSE OF THE ACONCAGUA RIVER
}

\begin{abstract}
Andrés Troncoso M.*
A partir del estudio de una serie de paneles de petroglifos existentes en el valle de Putaendo, en el río Aconcagua alto, se propone su clasificación en tres estilos de arte rupestre para la zona de estudio. Estos estilos se asociarían a los períodos Intermedio Tardío (900-1.400 d.C.), Tardío o Inca (1.400-1.536 d.C.) e Histórico (1.536 d.C. en adelante).

Palabras claves: Arte rupestre, estilos, Aconcagua.

This paper presents new archaeological research undertaken on the rock art of the Putaendo Valley. From the information gathering, we are proposing the existence of three styles of rock art associated with the Late Intermediate (900-1.400 A.D.), Late or Inca (1.400-1.536 A.D.) and Historical Periods (1.536 A.D. onwards).
\end{abstract}

Key words: Rock art, styles, Aconcagua.

Después de las primeras investigaciones realizadas por Niemeyer (1964) sobre el arte rupestre del curso superior del río Aconcagua, y salvo algunos aportes efectuados posteriormente por Igualt (1970) y Sanguinetti $(1968,1969)$, los trabajos sobre esta temática se estancaron. Una excepción a este caso es el intento de sistematización realizada por Mostny y Niemeyer (1983), sobre los diferentes estilos de arte rupestre existentes en Chile. Por nuestra parte, hace poco tiempo entregamos una síntesis interpretativa del arte rupestre de la zona de Putaendo desde la perspectiva de la arqueología del paisaje (Troncoso 1998). No obstante las posibilidades de tal trabajo, consideramos necesario volver a las raíces mismas del estudio del arte rupestre en esta zona: la ubicación temporal de las diferentes manifestaciones rupestres estudiadas.

A partir de las primeras investigaciones de Niemeyer (1964), se sostuvo la existencia de un solo estilo de arte rupestre en la zona, llamado estilo Aconcagua, definido por una variada temática en la que se "suelen mezclar motivos abstractos con formas estilizadas extremadamente disimuladas de la figura humana" (Mostny y Niemeyer 1983:63). El motivo que mejor definiría esta forma de arte sería el signo escudo, correspondiendo, en su forma más simple a un trapecio, a una elipse o a un trazado subrectangular, en el cual se han marcado dos diagonales. El diseño interior suele hacerse más complejo, con la introducción de puntos o pequeños círculos entre los sectores separados por las diagonales. En otras ocasiones dos de estos segmentos opuestos por el vértice se hacen de cuerpo lleno o un signo escudo va dentro de otro más grande (Mostny y Niemeyer 1983:66).

Múltiples formas geométricas complementarían este estilo de arte rupestre, entre las que se cuentan círculos, cruces inscritas, clepsidras, líneas en $\mathrm{V}$ y W, entre otros. Esta amplia variedad decorativa estaría relacionada entre sí por la presencia del signo escudo (Niemeyer 1964:145). El estilo Aconcagua se correspondería con la Cultura Aconcagua, debido a que coincidiría "en líneas muy generales con la difusión de la llamada cerámica Aconcagua Salmón, con cuya decoración los signos rupestres guardan cierto aire de familia" (Mostny y Niemeyer 1983:67).

Las investigaciones realizadas estos últimos años en el curso superior del río Aconcagua, princi-

\footnotetext{
* Laboratorio de Arqueología (LAr). Instituto de Estudios Gallegos Padre Sarmiento (CSIC-XuGa)/UA LaFC (IIT-USC). Santiago de Compostela, España. phandres@usc.es; atroncos@entelchile.net
} 
pal área de existencia de este arte rupestre y en específico en el valle de Putaendo (Figura 1), han venido a modificar los lineamientos clásicos que se proponían para esta zona. En específico, para el período Intermedio Tardío se ha demostrado que la Cultura Aconcagua no es la entidad característica de la zona, sino que más bien en esta área se darían desarrollos culturales propios, interdigitados con elementos de las culturas Aconcagua y Diaguita, lo que directamente afecta el conocimiento que teníamos sobre el estilo homónimo (Sánchez 2000a, 2000b), hecho que afecta directamente a los postulados que se manejaban para la asociación entre arte y cultura.

Esta modificación conceptual no es sólo propia del período Intermedio Tardío, sino que también se ha dado en el período Alfarero Temprano e Incaico. En el primer caso se observa para toda la cuenca superior del río Aconcagua la ausencia clara de un grupo homogéneo de poblaciones, primando más bien contextos múltiples y diferenciados espacialmente, contextos que en el caso del valle de Putaendo se caracterizan por presentar semejanzas con lo conocido para el valle del Choapa y la vertiente oriental de los Andes, así como ubicaciones cronológicas algo tardías (ca. 800 d.C.) (Pavlovic 2000; Pavlovic et al. 2002). Para el período incaico se reconoce que la cuenca superior del río Aconcagua es una zona de fuerte influencia del Tawantinsuyu. En particular en el valle de Putaendo se identificó una fortaleza incaica desconocida y sin registro etnohistórico, correspondiente al pucara de El Tártaro. Sugiere una importante ocupación de contingentes diaguita-incaicos en el curso medio del río Putaendo, así como una presencia más fuerte del Tawantinsuyu en este valle, avalada tanto por la arquitectura monumental del sitio como por la presencia de al menos unas ocho collcas.

Las modificaciones ocurridas en la conceptualización de la prehistoria local, unidas a la gran heterogeneidad que se observa en el registro rupestre de la zona, nos llevaron a reabordar el tema del arte rupestre en el valle de Putaendo, pero esta vez desde una perspectiva orientada a la definición y caracterización de estilos de arte rupestre. Para cumplir tal objetivo se definió un concepto de estilo y un conjunto de herramientas metodológicas coherentes con esta definición.

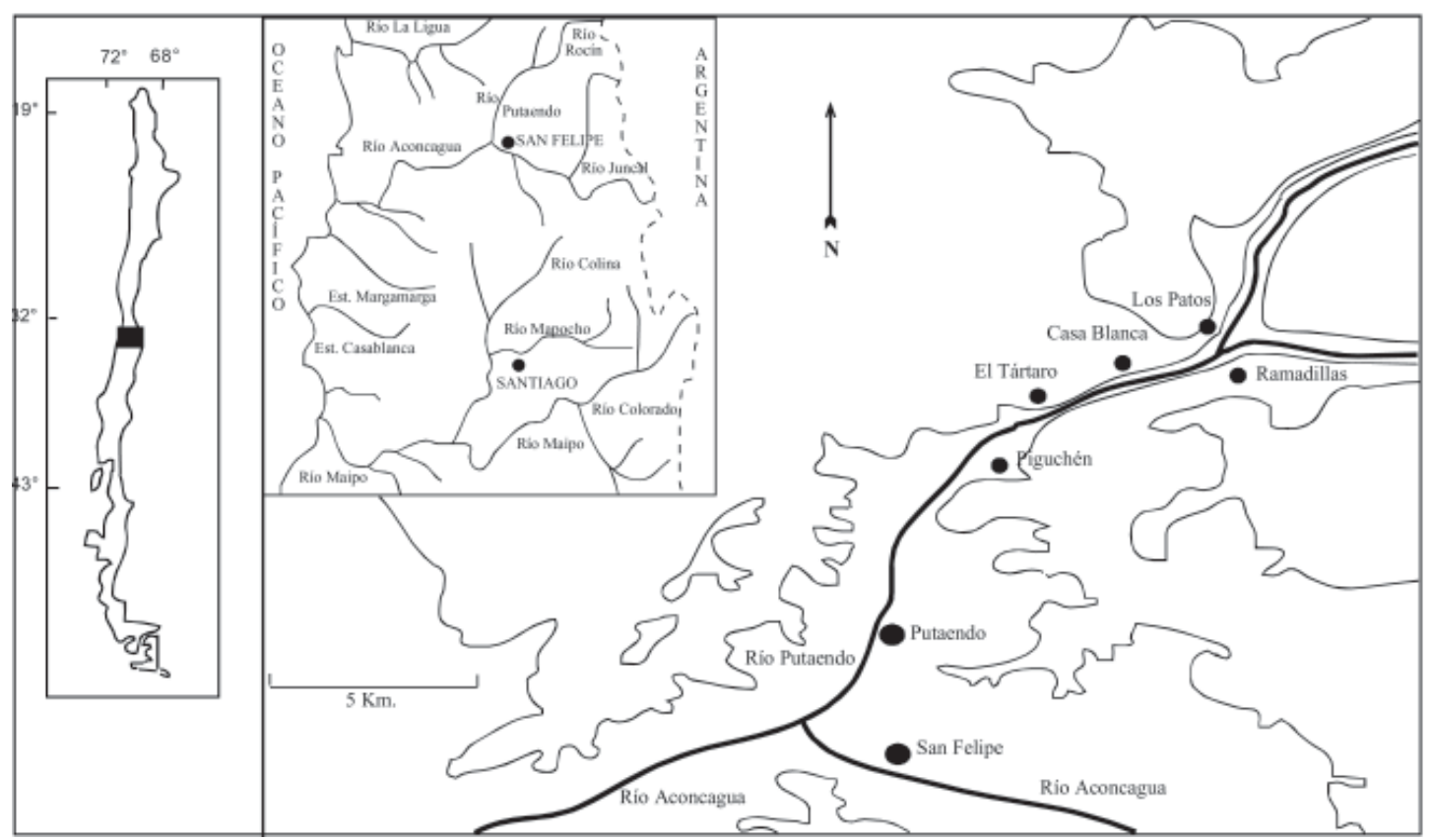

Figura 1. Área de estudio, valle de Putaendo, cuenca del Aconcagua.

Study area, Aconcagua basin, Putaendo valley. 


\section{El Concepto de Estilo}

Primordial a cualquier intento por definir diferentes tipos de arte rupestre es la clarificación y operacionalización del concepto de estilo, pues de ello depende todo el aparato teórico-metodológico que sustenta y legitima la investigación. Si bien existe una amplia literatura al respecto, tanto en arqueología como en historia del arte (p. ej. Conkey y Hastorf 1993; Kroeber 1969 [1957]; Morphy 1994; Panofsky 2000 [1995]), consideramos positivo intentar desarrollar una definición arqueológica de este término que permita su uso sistemático dentro de nuestro campo de estudio, básicamente, por cuanto muchas de las definiciones que se manejan o bien se enfocan en los aspectos funcionales del estilo (p. ej. los trabajos reunidos en el volumen de Conkey y Hastorf 1993) o, por el contrario, son definiciones cuyas características imposibilitan una operacionalización metodológica (p. ej. Panofsky 2000 [1995]).

El concepto de estilo debe dar cuenta de la realidad ya conocida por el investigador y ser una herramienta capaz de asimilar futuros resultados dentro de los parámetros que han sido definidos como característicos para cada estilo. Así, y al entender el arte rupestre como una variable de carácter politético, creemos que una definición de estilo a partir de la simple agregación de figuras no es suficientemente rentable para la investigación, pues falla al ser incapaz de dar cuenta de la lógica que guía toda la producción visual rupestre y desconoce el hecho que la cantidad de motivos componentes de un estilo pueden ser, y de hecho lo son, demasiado extensos para ser abarcados en una descripción sumaria.

Un estilo es para nosotros un conjunto de normas determinadas por un sistema de saber-poder (Foucault 1992), que definen una forma particular de inscripción gráfica, transformándose ésta en la concreción material de tal sistema. El estilo se expresaría en: (i) la generación de una serie de motivos politéticos que presentan algunas de estas reglas $^{1}$; (ii) una determinada técnica de producción de las figuras; (iii) una determinada definición de los soportes a utilizar; (iv) una determinada localización espacial, y (v) una determinada articulación de los motivos al interior del panel.
Pretendemos entender entonces el estilo como un sistema normado amplio, normado por cuanto toda la producción del arte rupestre se remite a un sistema mayor, amplio, porque más que definir una normativa estricta el estilo permite una amplitud de creación de acuerdo a sus presupuestos. El estilo más que estar constituido por un número finito de figuras permite la generación de un amplio abanico de motivos. En otras palabras, los estilos son “dominios prácticos limitados por sus fronteras, sus reglas de formación, sus condiciones de existencia" (Foucault 1991[1968]:60). Esta noción puede ser comparable con la de formación discursiva propuesta por Foucault (1997[1970]). Una formación discursiva hace referencia a un conjunto de enunciados que dentro de su dispersión presentan una cierta regularidad (formal, enunciativa, posicional). Esta regularidad permite cierto tipo de enunciados y cierta manera de enunciación. Ejemplificando con el caso de la locura Foucault (1997[1970]:53) ${ }^{2}$ sugiere que la unidad de los discursos sobre la locura no estaría fundada sobre la existencia del objeto locura, o la constitución de un horizonte único de objetividad: sería el juego de las reglas que hacen posible durante un período determinado la aparición de objetos.

\section{Metodología}

Considerando la definición de estilo manejada en la presente investigación, y las diferentes dimensiones materiales en las que se debería plasmar, se crearon tres fichas de registro para la recolección de los datos en terreno. Cada una de estas fichas se elaboró de acuerdo a la dimensión de estudio que se pretendió abarcar: sitio, panel y motivo.

1. Sitio: se relevó un conjunto de datos relativos a la ubicación del sitio, emplazamiento, número de paneles de arte rupestre; asociación a recursos hídricos, sitios arqueológicos de tipo habitacional y rutas de movimiento. Las condiciones de visibilización (campo visual que se abarca desde el sitio) y visibilidad (capacidad de ser observado desde otros lugares) fueron atributos también considerados (Criado 1999). Los atributos discriminados para este nivel de análisis tienen como objetivo entregar una caracterización sobre la disposición espacial de los sitios de arte rupestre. 
2. Panel: tipo de soporte (materia prima, características de la superficie, atributos métricos), orientación, tipo de motivos presentes, existencia de superposiciones y yuxtaposiciones más la disposición de los motivos al interior del soporte fueron considerados atributos significativos de este registro en este nivel de análisis. A través de ellos, un acercamiento a las normas que regulan la construcción del panel es posible de realizar ${ }^{3}$.

3. Figuras: debido a la existencia de figuras geométricas, antropomorfas y algunas zoomorfas al interior de la muestra de estudio, cada una de ellas fue relevada de acuerdo a un conjunto de parámetros exclusivos.

a) Figuras geométricas, al entender al estilo como un constructo determinado por un sistema de saber-poder, va implícito el hecho que diferentes formas de estar en el mundo, y por tanto de entenderlo, generan expresiones rupestres disímiles en sus normas constructivas. Por ello, en el caso de los elementos geométricos se decidió describirlos en primer lugar a partir de la unidad geométrica mínima de construcción: círculo, cuadrado, triángulo; si ninguna de estas categorías era concordante con lo observado se añadieron los conceptos de lineal y otro. Definida su unidad mínima, se describió la existencia de decoración interior y su tipo (punto central, trazos, círculos, etc.), la presencia de apéndices y su tipo (lineal, circular), la existencia de superposiciones y yuxtaposiciones con otro motivo, sus características métricas (largo, ancho y grosor de su surco) y la técnica de su construcción. Con el fin de no perder de vista el universo representacional a través del cual se expresa el estilo, se realizó también la descripción de la figura resultante de la suma de los atributos antes señalados.

b) Figuras antropomorfas, junto con describirlas en su totalidad, se registró el conjunto de atributos corporales-humanos que la figura presentaba (cabeza, ojos, boca, tronco, extremidades, sexo, etc.), la presencia de rasgos dinámicos que afectasen al tronco y extremidades, la postura del individuo (de frente o de perfil; de pie, inclinado, sentado), sus condiciones de animación (referentes al tipo de acción expresión representada en la imagen, Gallardo et al. 1996), los atributos métricos del personaje (ancho y alto máximo, más algunas proporciones corporales), la presencia de otro tipo de figuras en directa asociación con el individuo (penachos, faldellines, etc.), superposiciones, yuxtaposiciones y la técnica constructiva.

c) Figuras zoomorfas, se describieron atributos similares a los mencionados para las figuras humanas, realizando algunas variaciones en lo que a postura se refería y añadiendo el tipo de conducta que sugería la cola más las orejas del cuadrúpedo (agresiva, pasiva, etc.).

Para los tres conjuntos de motivos también se discriminó el estado de conservación de la figura.

La información recolectada a partir de este último nivel de análisis es la que entrega los principales fundamentos para la definición de un estilo, pues a través de la variación formal de los atributos es posible avanzar en la discriminación de diferentes elaboraciones significativas y, por ende, diferentes sistemas de saber-poder que producen en su materialidad estilos de arte rupestre disímiles.

\section{Resultados}

A partir de prospecciones sistemáticas realizadas en las localidades de Casa Blanca (de aquí en adelante C.B.), El Tártaro, Ramadillas y Piguchén, todas ubicadas en el curso medio y superior del río Putaendo (Figura 1), se logró identificar un total de 27 estaciones de arte rupestre. De este universo, se trabajaron 18 sitios, debido básicamente a que, mientras un par de estaciones presentaba los paneles muy erosionados (C.B. 3 y 13), en otras ocasiones no se contó con todas las herramientas necesarias para el fichaje de los sitios (p. ej. sitios de la localidad de El Tártaro). En la Tabla 1 se resumen las características de todas las estaciones identificadas, indicando qué tipo de trabajo fue realizado en cada una de ellas. No obstante lo anterior, y debido a la importancia de las estaciones de arte rupestre localizadas en El Tártaro, se consideran de manera general en la discusión de los estilos presentes en el área.

Del total de sitios analizados, se trabajó un total de 375 figuras, $332(88,5 \%)$ de las cuales corresponden a elementos geométricos, $42(11,2 \%)$ a figuras antropomorfas y una a zoomorfo $(0,3 \%)$. A continuación se presenta una descripción de los resultados obtenidos, centrándonos básicamente en 
Tabla 1. Sitios de arte rupestre identificados en el valle de Putaendo. Rock art sites, petroglyphs, identified in the Putaendo valley.

\begin{tabular}{|c|c|c|c|}
\hline Sitio & UTM Norte & UTM Este & Tipo de trabajo \\
\hline Casa Blanca 2 & 6400517 & 345354 & Registro \\
\hline Casa Blanca 3 & 6400497 & 345715 & Identificación \\
\hline Casa Blanca 6 & 6400831 & 345560 & Registro \\
\hline Casa Blanca 8 & 6400612 & 345264 & Registro \\
\hline Casa Blanca 13 & 6401278 & 344392 & Identificación \\
\hline Casa Blanca 14 & 6401349 & 344138 & Registro \\
\hline Casa Blanca 24 & 6400632 & 347165 & Registro \\
\hline Casa Blanca 26 & 6400530 & 346777 & Registro \\
\hline Casa Blanca 27 & 6400304 & 346609 & Registro \\
\hline Casa Blanca 28 & 6400178 & 346533 & Registro \\
\hline Casa Blanca 29 & 6400479 & 346888 & Registro \\
\hline Casa Blanca 29b & 6400446 & 346719 & Registro \\
\hline Casa Blanca 32 & 6401301 & 343934 & Registro \\
\hline Casa Blanca 33 & 6401309 & 343950 & Registro \\
\hline Casa Blanca 34 & 6401275 & 344164 & Registro \\
\hline Ramadillas 5 & 6401547 & 350989 & Registro \\
\hline Ramadillas 6 & 6401401 & 350534 & Registro \\
\hline Piguchén 2 & 6395060 & 348235 & Registro \\
\hline Piguchén 3 & 6395018 & 347511 & Identificación \\
\hline Piguchén 5 & 6395280 & 346817 & Registro \\
\hline Piguchén 6 & 6395094 & 345849 & Registro \\
\hline El Tártaro 1 & 6399100 & 342900 & Identificación \\
\hline El Tártaro 2 & 6400241 & 342704 & Identificación \\
\hline El Tártaro 3 & 6400265 & 342810 & Identificación \\
\hline El Tártaro 4 & 6400023 & 342696 & Identificación \\
\hline El Tártaro 5 & 6399491 & 342817 & Identificación \\
\hline El Tártaro 7 & 6399949 & 343792 & Identificación \\
\hline
\end{tabular}

la definición de estilos a partir de las características de las figuras, dejando de lado por este momento el análisis del panel.

\section{Las Formas del Arte}

\section{Figuras geométricas}

Se registró una gran variedad con respecto a la geometría de su unidad mínima de construcción. Aún así, hay un significativo predominio de las formas circulares $(81,3 \%)$ por sobre el restante universo representacional compuesto por cuadrados $(9,7 \%)$, líneas $(6,9 \%)$, otros $(1,2 \%)$ y triángulos $(0,9 \%)$ (Figura 2$)$.

A) Círculos: La figura circular se presenta con dos modalidades constructivas básicas: decoración interna y presencia de apéndices. Al observar el registro de estos dos atributos se aprecia una mayor frecuencia de figuras sin decorar en comparación con aquellas decoradas. En cambio, el registro de presencia y ausencia de apéndice es casi idéntico para esta forma decorativa (Tabla 2). El entrecruzamiento de ambos atributos en las figuras circulares muestra la ausencia de algún tipo de correlación.

Con respecto a las características que asume la decoración interior de las figuras circulares se dio cuenta de la presencia de una alta frecuencia de punto central (42\%), seguido por el círculo concéntrico simple ${ }^{4}(24 \%)$, trazos $(22 \%)$ y círculo concéntrico compuesto (10\%). Dentro del universo de los círculos concéntricos se observa la presencia de figuras sin decoración interior y otras con decoración interior, consistentes ya sea en puntos centrales, trazos horizontales, verticales y/o la combinación de todos estos elementos. Todos estos dispositivos decorativos se disponen en el espacio interior definido por el círculo concéntrico menor (Figura 3). Las estrategias decorativas observadas en la aplicación de trazos al interior de los círculos 


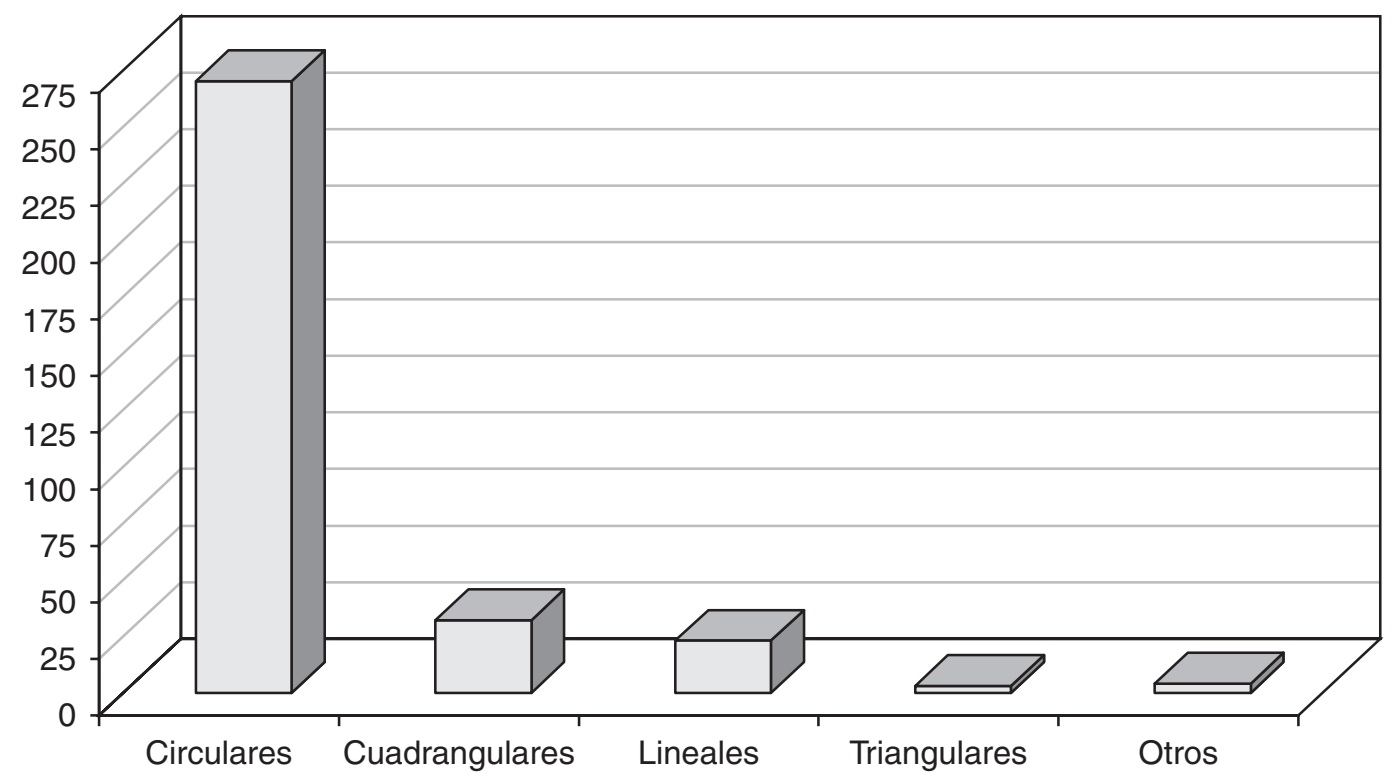

Figura 2. Frecuencias de formas geométricas del arte rupestre en el valle de Putaendo.

Frequency of geometric designs in rock art, Putaendo valley.

concéntricos se materializan en la creación de motivos cuatripartitos, bipartitos y enrejados, algunos de los cuales caen dentro de la categoría de signos escudos.

Entre las figuras circulares los apéndices varían desde la aplicación de simples trazos lineales por el exterior de la figura, hasta la anexión de un variado número de figuras circulares y la unión hacia otros motivos a partir del trazado de una línea. La solución más utilizada en lo que a apéndices se refiere es la unión a otra figura y la ejecución de trazos lineales. A veces estas características inducen a interpretarla como una figura, lo que sólo es parte de una figura mucho mayor, o viceversa, un gran motivo no es más que la suma de pequeñas figuras. Creemos que tal ambigüedad en la construcción de los motivos no es totalmente adscribible al tipo de análisis realizado, sino que es más bien parte de una estrategia constructiva ambigua de las figuras rupestres.

La ausencia de relación entre decoración y apéndice es significativa se vuelve a encontrar al analizar la correlación entre el tipo de apéndice y la decoración, aunque existen algunas excepciones. En el caso del círculo concéntrico simple sin decoración interior, los apéndices se encuentran en un $15,8 \%$ de los casos, mientras que su variedad decorada aparece en un $35,8 \%$ de los casos. La si-
Tabla 2. Relación entre apéndices y decoración en figuras circulares.

Relationship between appendix and decoration of circular designs.

\begin{tabular}{lccc}
\hline Atributo & Apéndice (+) & Apéndice (-) & Total \\
\hline Decoración (+) & $13,2 \%$ & $26,7 \%$ & $39,9 \%$ \\
Decoración (-) & $39,1 \%$ & $21 \%$ & $60,1 \%$ \\
\hline Total & $52,3 \%$ & $46,7 \%$ & $100 \%$ \\
\hline
\end{tabular}

$(+)=$ Presencia,$(-)=$ Ausencia.

tuación es más drástica al interior del círculo concéntrico compuesto donde no existen apéndices en ninguna de las dos variantes del motivo, decorada y no decorada. Entre los círculos con punto a manera de dispositivo decorativo, se observa que en un 90,5\% existe algún tipo de apéndice, básicamente correspondiente a la unión con otra figura. Lo anterior sugiere una posible asociación entre círculos concéntricos compuestos y ausencia de apéndices y círculos con puntos y presencia de apéndices.

Aunque las correlaciones de momento observadas son escasas y poco representativas, no es menos cierto que a partir de la combinación de estos atributos se generan gran parte de las figuras 


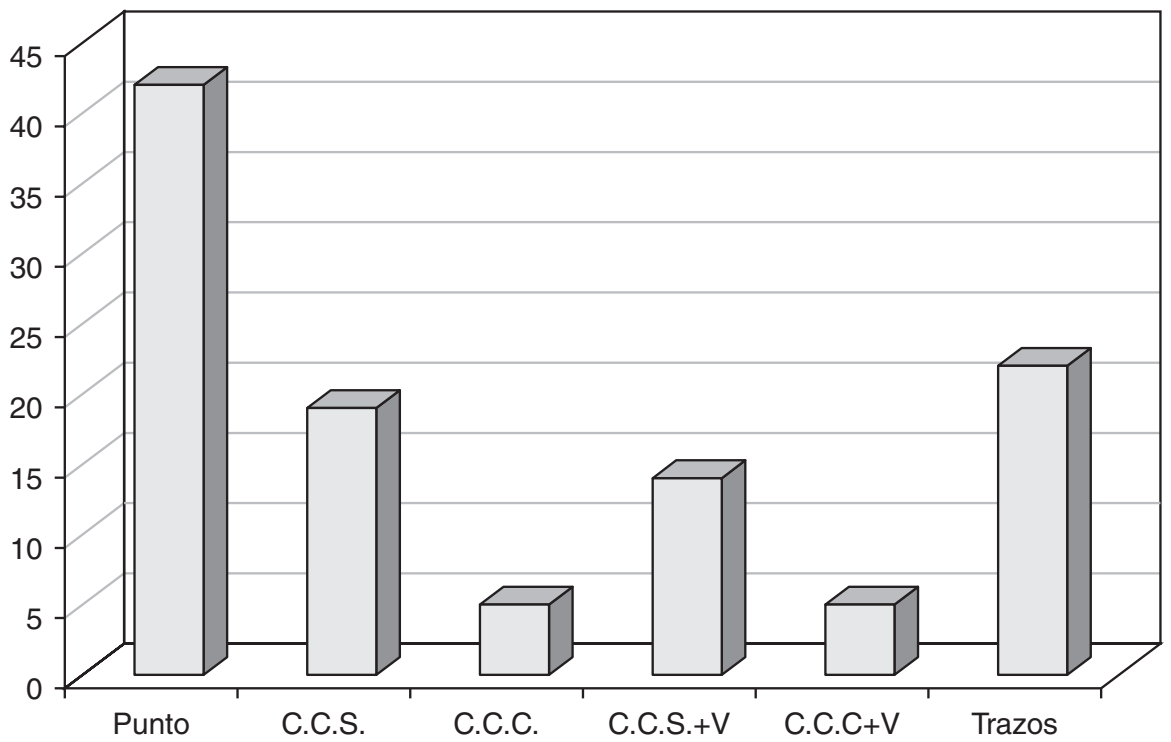

Figura 3. Decoración interna de círculos. CCS: círculo concéntrico simple, CCC: círculo concéntrico compuesto, $\mathrm{CCS}+\mathrm{V}$ : círculo concéntrico simple más variante, $\mathrm{CCC}+\mathrm{V}$ : Círculo concéntrico compuesto más variante. Internal circle decorations. CCS: simple concentric circle, CCC composite concentric circle, CCS+V: simple concentric circle plus variant, $C C C+V$ : composite concentric circle plus variant.

geométricas del arte rupestre del valle de Putaendo. De hecho, es tan fuerte su representación que inclusive a partir de la aplicación de estas mismas conjunciones se generan algunas figuras humanas. La única excepción es la existencia de dos espirales en el sitio C.B. 8, las que se disponen en la cara frontal de un alero con restos de ocupación humana. En este mismo sitio, existe otro panel de arte rupestre dispuesto sobre la cara superior del alero con un conjunto de motivos circulares que presentan el conjunto de características mencionadas para la totalidad de este tipo de motivos.

B) Cuadriláteros: Las figuras con (o de) cuatro lados, cuadrangulares, se encuentran representadas en 32 motivos rupestres. Es importante indicar que la gran mayoría de estos motivos se registraron en los sitios localizados en la localidad de Ramadillas (66\%). En términos generales, del total de figuras cuadrangulares, un $59,4 \%$ presenta algún tipo de decoración, consistente básicamente en la aplicación de trazos lineales en su interior (Tabla 3). Con respecto a los apéndices, su distribución se resume en el Tabla 4.

A partir de la aplicación de trazos en la decoración interior se generan motivos como el signo escudo y figuras cuatripartitas o con un enrejado interior. Excepcionales en este contexto son el cuadrado concéntrico existente en C.B. 14, una figura cuadrada de cuerpo relleno y un paralelogramo con un círculo incluido. Finalmente, cabe decir que el único trapezoide se encuentra registrado en el sitio C.B. 33. Presenta una decoración circular interior y no posee apéndices. A lo anterior se suma el hecho de encontrarse bajo un borrado intencional de algunos motivos, borrados que abarcan parte de esta misma figura.

C) Triángulos: Registrados solamente en tres casos, uno corresponde a una clepsidra identificada en el sitio C.B. 14, sin decoración ni apéndice; otra figura posiblemente triangular se registra en el sitio C.B. 27, no presenta decoración y sí un apéndice lineal. La extraña construcción de esta figura hace difícil su descripción. Un tercer triángulo sin apéndice ni decoración se encuentra en el sitio Ramadillas 6. Es importante indicar que esta figura se asocia a otros motivos poco frecuentes como cuadrados, uno de ellos con una figura circular a manera de decoración interior.

D) Lineales: No obstante que este motivo se encuentra registrado en 23 casos, su distribución al interior de las estaciones de arte rupestre es baja, 
Tabla 3. Decoración figuras cuadrangulares. Decoration of square designs.

\begin{tabular}{lc}
\hline Decoración & Porcentaje \\
\hline Trazos lineales & 73,5 \\
Paralelogramo concéntrico & 5,3 \\
Punto central & 5,3 \\
Paralelogramo con cuerpo relleno & 5,3 \\
Círculo interior & 5,3 \\
Círculo incompleto & 5,3 \\
\hline Total & 100 \\
\hline
\end{tabular}

Tabla 4. Apéndices en figuras cuadrangulares. Appendages in square designs.

\begin{tabular}{lc}
\hline Decoración & Porcentaje \\
\hline Decorada & 35,4 \\
No decorado & 72,5 \\
\hline
\end{tabular}

ya que se encuentra presente en los sitios C.B. 6 (47,8\%), C.B. 14 (26,1\%), Ramadillas 6 (13\%), C.B. $33(8,7 \%)$ y C.B. $27(4,4 \%)$.

De este número de figuras lineales, existen tres (13\%) que corresponden a cruces presentes en C.B. $6 \mathrm{y}$ dos figuras $(8,7 \%)$ inscritas a manera de "I" latina mayúscula en el sitio C.B.14. Una figura que recuerda a las anteriores, aunque con una elaboración más tosca se encuentra en C.B. 27. También se encuentran algunas figuras que asemejan letras "T" y "H" más algunos zigzag y cruces cristianas. En general, este tipo de motivos son poco claros al interior del registro y una gran diversidad de figuras son reconocibles. En algunos casos motivos como zigzag no sólo actúan a manera de unidades aisladas, sino que son también partes de trazos complejos que unen figuras. Del total de 23 casos, un $26,7 \%$ registra apéndices, correspondiendo en frecuencias similares a uniones a otras figuras y a trazos lineales.

E) Signo escudo: Aunque figuras de este tipo caen dentro de las categorías revisadas en los párrafos anteriores, no queremos terminar esta presentación sobre las figuras geométricas del valle sin referirnos en forma exclusiva al conocido signo escudo, hipotético emblema del llamado estilo Aconcagua (Mostny y Niemeyer 1983). En el área estudiada por nosotros hemos registrado solamente 13 de estas figuras, representándose básicamente en el área de Ramadillas, donde en un panel se observa una importante concentración de este motivo. Sus características de construcción hacen referencia a la utilización de trapecios $(46,1 \%)$ y círculos $(53,9 \%)$ como elementos geométricos para su elaboración. Su decoración interior, como lo plantea Niemeyer (1964), se basa en la aplicación de trazos horizontales y diagonales que generan decoraciones interiores enrejadas y cuatripartitas. La presencia de apéndices en estas figuras es ínfima $(7,7 \%)$, mientras que las yuxtaposiciones se presentan en un número mayor $(30,7 \%)$, con otros signos escudos o con algún tipo de figura geométrica.

\section{Figuras humanas}

Se encuentran representadas por 42 figuras, registradas en 9 sitios. Con objetivos de análisis, y con base en los sistemas de representación de los antropomorfos se dividen estas figuras entre las que tienen un bajo grado de esquematización y aquellas que presentan una mayor codificación en su estructura, pero sin dejar de perder por ello su semejanza con lo humano. No se trata con ello de crear una tipología tan básica de la figura antropomorfa, sino de abordar las diferentes maneras de representar al ser humano en su propia dispersión, comparando los atributos propios manejados para cada uno de estos dos subgrupos, para posteriormente intentar una comprensión global de las formas de representación de las figuras antropomorfas.

A) Antropomorfos I: Corresponden a 23 figuras humanas que se encuentran presentes en los sitios C.B. 2, 26, 33, Piguchén 2, 5 y 6 . Todas estas representaciones del ser humano se caracterizan por presentar un bajo nivel de esquematización en su construcción.

Un primer punto sugerido por el análisis de la representación humana es el registro de 9 motivos que forman parte de los antropomorfos. Un 77,7\% de ellos corresponde a apéndices lineales que surgen desde la cabeza del individuo y que podrían ser interpretados como tocados. Los restantes corresponden a una figura lineal que recuerda algún artefacto tipo bastón y una figura zoomorfa de la cual hablaremos más adelante.

Las formas de representación del ser humano se caracterizan por una cierta proporcionalidad 
entre las diferentes secciones del cuerpo. Es recurrente que las piernas nunca sean más largas que el tronco y que, al contrario, las extremidades superiores en repetidas ocasiones se presenten métricamente exageradas. Las representaciones del cuerpo guardan también una cierta relación. La cabeza humana se registra en todos los casos por una figura circular, a excepción de un caso en C.B. 26 donde ésta adquiere una forma achatada y dos casos en C.B. 33, donde no es más que un punto. Del total de figuras circulares 7 presentan punto central. Respecto a la representación de otros sectores del cuerpo humano, en la Tabla 5 se indican qué partes del cuerpo se referencian y su frecuencia. Sólo ojos, boca y oreja nunca se explicitan en este arte, siendo una variable no dependiente del tamaño, por cuanto existe una homogeneidad métrica en todas las representaciones humanas estudiadas.

Con respecto a las posiciones que adquieren estas figuras en su construcción, encontramos que todas están de frente, de éstas, $86,9 \%$ se encuentran también de pie, $8,7 \%$ sentadas y un $4,4 \%$ en posición indeterminada. La animación en todos los casos es nula, con $8,7 \%$ ejemplos de animación flectada, $78,2 \%$ oblicua, $4,4 \%$ vertical y $8,7 \%$ no definidas. Evidencias de algún tipo de gesto, es decir movimiento, es casi inexistente, con un solo caso confirmado de presencia de este atributo más dos posibles. Otro atributo que permite adentrarse a las características de animación de la figura humana son los ángulos que presentan brazos y piernas, constatándose en este hecho que para el primer caso hay una alta presencia de figuras de este tipo $(65,2 \%)$ y una menor representación del segundo caso $(30,4 \%)$.

Tabla 5. Representación del cuerpo en figuras humanas. Body representation in human designs.

\begin{tabular}{lr}
\hline Cuerpo & Porcentaje \\
\hline Tronco & 95,6 \\
Extremidades superiores (2) & 95,6 \\
Extremidades superiores (4) & 4,4 \\
Extremidades inferiores (1) & 13 \\
Extremidades inferiores (2) & 86,9 \\
Manos & 13 \\
Posibles manos & 17,4 \\
Pies & 4,4 \\
Sexo masculino & 52,2 \\
\hline
\end{tabular}

$\mathrm{Al}$ entrecruzar los atributos relevados se observa que todos los personajes con una clara definición de su sexo masculino se encuentran de pie y preferentemente en animación oblicua $(83,4 \%)$, con baja representación de animación flectada y vertical ( $8,3 \%$ en cada caso). Finalmente, dentro de este universo se encuentran tres figuras rellenas, en un caso corresponde a un brazo y en los dos restantes a cuerpos.

B) Antropomorfos II: Representados por 19 figuras registradas en los sitios C.B. 6, 14, 34 y 33: A diferencia del caso anterior, estas representaciones antropomorfas se caracterizan por poseer un mayor grado de esquematización en la construcción de la figura humana, lo que redunda en una creación más geométrica que los distancia con las figuras anteriormente expuestas.

La geometría de la figura humana se origina en este caso básicamente a partir de un círculo $(84,2 \%)$, con algunas excepciones constituidas por líneas $(10,5 \%)$ y una figura no definida $(5,3 \%)$. De los 16 círculos que originan la representación del ser humano, un $25 \%$ no presentó decoración interior; entre las figuras lineales ninguna presentó decoración interior obviamente. En la Tabla 6 se resumen las características decorativas existentes al interior de los círculos de las figuras humanas. En este sentido, el registro de elementos asociados a la figura humana es menos representativo que el caso anterior, correspondiendo solamente a un $25 \%$ de los casos la mitad de ellos un tipo lineal no interpretable y en los otros a uno lineal asimilable a un tocado con forma de antena y el mencionado rectángulo que recuerda un gorro.

Tabla 6. Tipos de decoración interior figuras humanas. Types of decoration inside human designs.

Representación

Porcentaje

Círculo concéntrico simple con

punto central

38,5

Punto central

30,7

Círculo concéntrico simple

15,4

Círculo concéntrico compuesto

7,7

Relleno interior (tocado rectangular

tipo gorro)

7,7 
Con respecto a la representación del cuerpo humano, encontramos una forma de exhibición similar del tronco. En el caso de la cabeza, su representación es algo más variada discriminándose básicamente una casi total representación a partir de la elaboración de círculos, simples o concéntricos. Cabe decir que en algunas ocasiones el círculo concéntrico también se ha utilizado como significante de la pelvis. Como en el caso de las otras figuras humanas, todas se encuentran de frente y presentan una animación nula.

\section{Figuras zoomorfas}

El único caso de figura zoomorfa se encuentra en el sitio C.B. 33, representado por un cuadrúpedo en yuxtaposición con una figura humana en una escena de monta. Técnicamente, el animal ha sido elaborado de la misma forma que todo el arte rupestre del valle ${ }^{5}$.

\section{Las Reglas del Arte: Superposiciones y Yuxtaposiciones}

A partir de nuestro concepto de estilo definido en un principio, creemos de vital importancia abordar inicialmente el tema de las yuxtaposiciones y superposiciones, pues son estas dos soluciones que configuran la producción rupestre, por lo que tienen directa influencia con la manera en que los motivos son representados y las escenas construidas.

1. Yuxtaposiciones: Correspondiente a figuras que comparten un mismo segmento de surco del trazado, una solución frecuentemente utilizada en el arte local y se encuentra en 111 casos de la muestra estudiada. Dentro de las figuras geométricas se registró en un $92,8 \%$ de los casos, coincidiendo básicamente con una representación exclusiva de los motivos circulares $(80,7 \%)$, situación esperable debido a la alta frecuencia de esta figura en el arte local.

La yuxtaposición es utilizada en estos casos como solución básica para la construcción de algunas representaciones complejas, tales como círculos aglutinados, o para unir figuras que pueden corresponder a dos elementos diferentes, o constituir una sola gran figura. Ejemplos clásicos de este último caso son círculos que se encuentran distanciados al interior del panel, pero que en su construcción se unen a partir de la aplicación de apéndices lineales.

Entre las figuras cuadrangulares se encontró en un bajo número de casos, particularmente en los signos llamados escudos, registrándose uniones con otras figuras disímiles o con otros signos escudos. La yuxtaposición es un hecho mucho más aislado entre las representaciones de la figura humana, encontrándose presente en 8 casos, anexándose tanto a elementos geométricos como a otras representaciones humanas.

2. Superposiciones: Con una menguada representación al interior de la muestra estudiada, se logró identificar un total de 6 casos. Una superposición se presenta en los sitios C.B. 33 y El Tártaro 1, mientras que dos superposiciones están presentes en los sitios C.B. 34 y C.B. 14. Debido a la poca recurrencia de este hecho y a las características diferenciales que presenta cada superposición es que serán analizadas en detalle cada una de ellas a continuación.

En el caso de C.B. 33, la superposición identificada representa una lógica que no se registra en otro motivo. Encontramos aquí que dos motivos muy próximos entre sí presentan un borrón intencional de sus lados más próximos. Este borrado ha sido efectuado a partir del raspado del área con un artefacto lítico (Figura 4). En los dos casos registrados en el sitio C.B. 34 la situación es diferente y tiene una cierta lógica gramatical en su construcción, lo que nos lleva a sospechar en una estrategia diferencial de producción de esta superposición. En estos dos casos, registrados en el mismo panel, lo que encontramos es que una figura humana se encuentra dispuesta a partir de un círculo concéntrico con punto a la altura de su cuerpo (Figura 5f). Aunque no podemos interpretar el significado de este hecho, creemos que es posible a lo menos bordear los contornos del sentido de este acto a partir de las características del contexto rupestre estudiado. De este modo esta superposición tiene una cierta lógica, ya que el artista no está más que aprovechando en una forma económica el círculo previo como referente corporal para la nueva figura que se superpone a ella, solución que es totalmente coherente con la lógica del arte local, pues como ya vimos, en un número importante de casos hemos encontrados que el cuerpo, cabeza y/o pelvis del individuo se encuentra representado por esta figura geométrica (Figuras 5b, c, d y f). Al respec- 


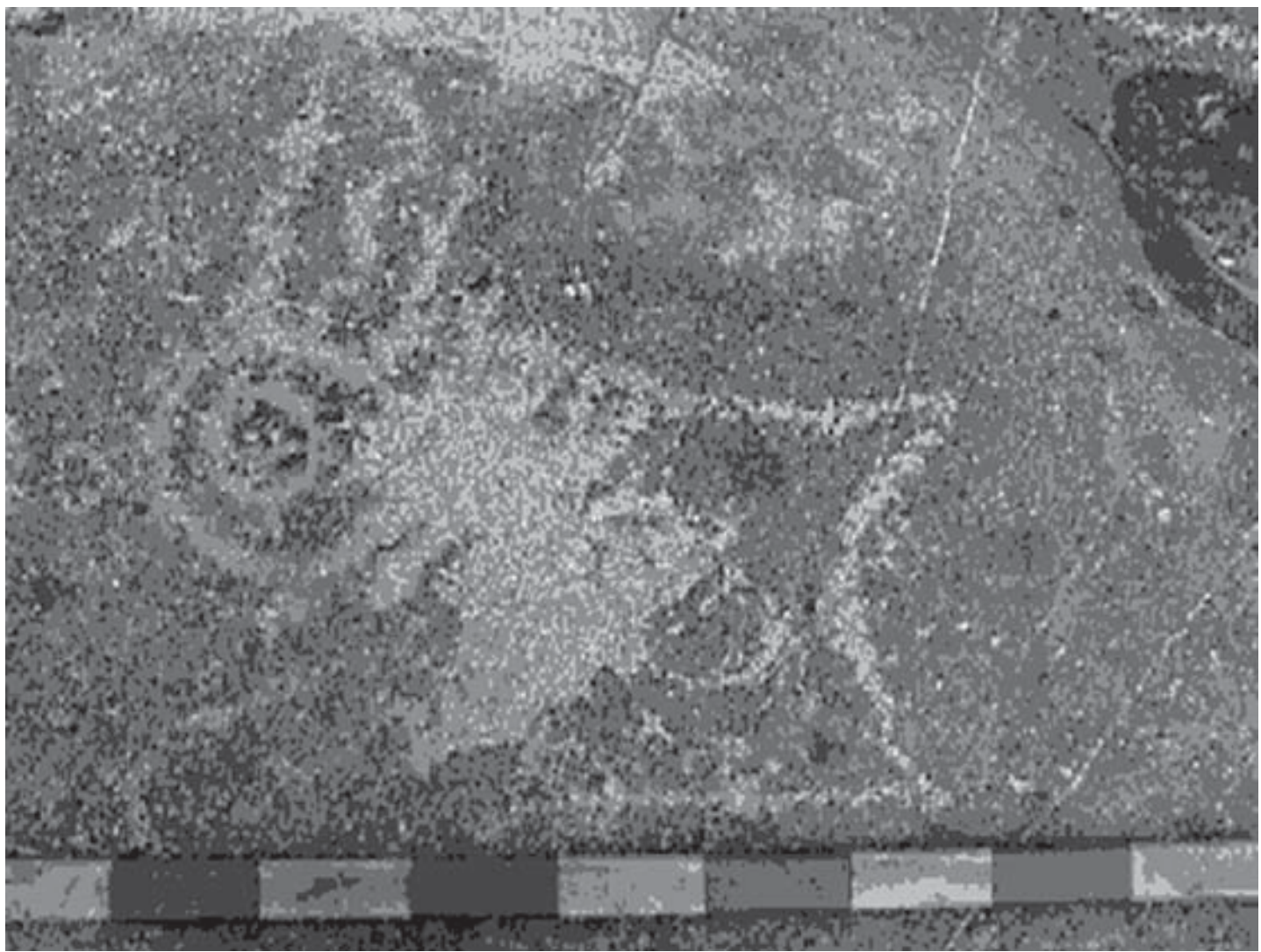

Figura 4. Motivos geométricos bajo un raspaje. Sitio Casa Blanca 33.

Geometric motif under a scraped surface. Site Casa Blanca 33.

to, un importante dato puede ser sugerido por los atributos métricos de ambas superposiciones, pues esta lógica gramatical de la articulación de los diseños se expresa también en el grosor de las figuras, donde los motivos en superposición presentan grosores similares (1 a 1,4 cm).

Diferente es la situación en el caso del sitio C.B. 14, ya que ahí lo que encontramos es la superposición de un cuadrado concéntrico compuesto sobre una figura circular (Figura 6). En este caso, junto con no tener ninguna relación lógica entre las figuras, encontramos una profunda diferencia en el grosor del motivo, donde el motivo inferior presenta un grosor de $0,8 \mathrm{~cm}$, mientras que el superior posee uno de $2,6 \mathrm{~cm}$. Significativo es en este caso también el hecho que la superposición se ubica en el sector central del panel principal de arte rupestre del valle y en un lugar fácilmente observable desde la ruta de movimiento-tránsito.

El último caso está presente en el sitio pucara El Tártaro, donde sobre una figura lineal de surco grueso se superpone un motivo cuadrangular de lados curvos de surco más delgado, posiblemente elaborado con un instrumento metálico.

\section{Discusión: Los Estilos del Arte}

El conjunto de figuras estudiadas a lo largo del valle de Putaendo presenta cierta homogeneidad entre sí. La presencia de algunas variaciones en la construcción de las figuras nos hace pensar, sin embargo, en la posibilidad de la existencia de más de un estilo de arte rupestre. Esta afirmación se basa tanto en los datos aquí expuestos como en el registro inicial de los paneles de petroglifos que se encuentran en asociación con el sitio pucara El Tártaro y que serán mencionados en su oportunidad.

Los estilos de arte rupestre presentes en el valle de Putaendo serían tres y se asociarían respectivamente al período Intermedio Tardío, Tardío e Histórico; este último podría ser dividido cronoló- 

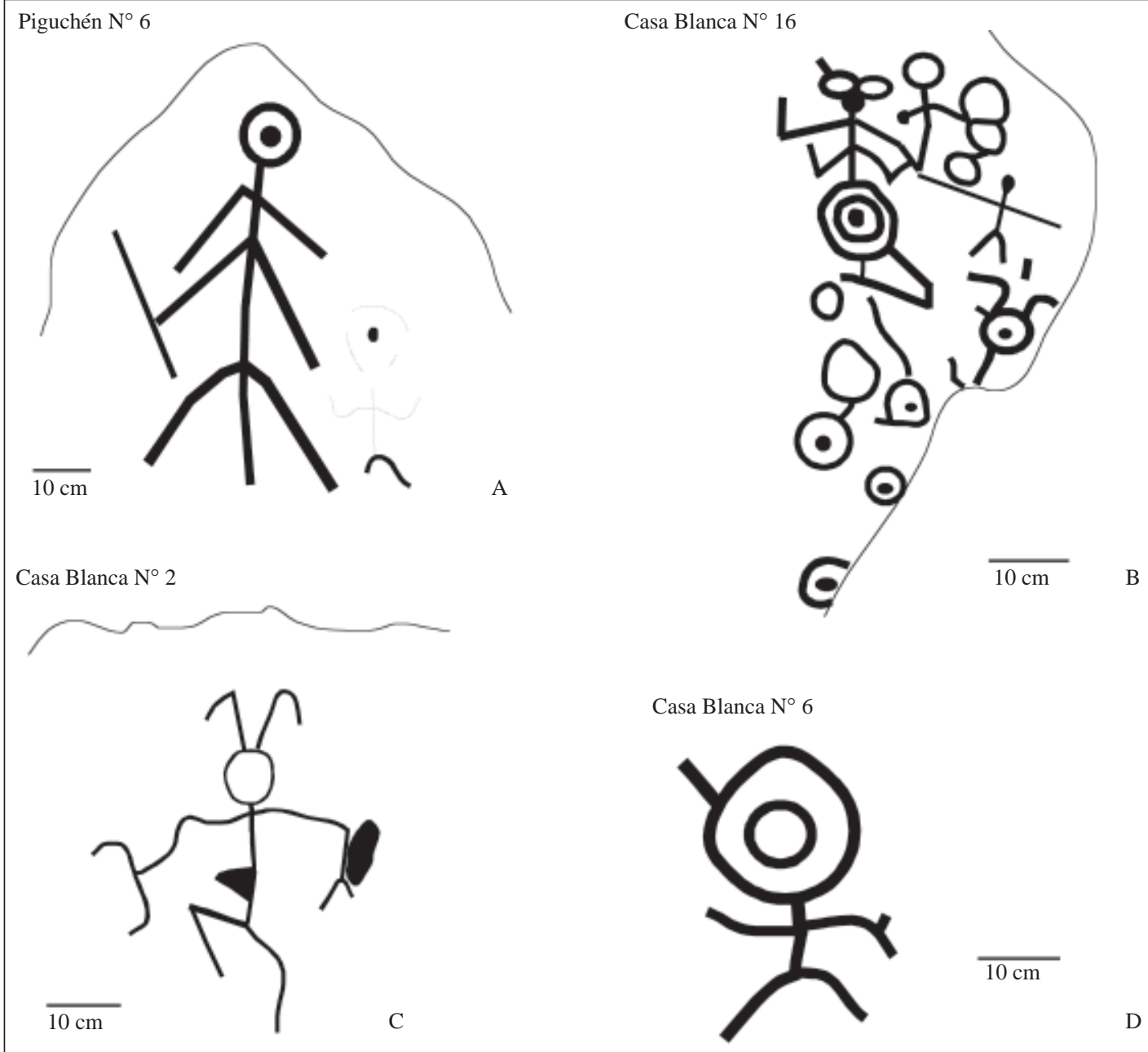

Piguchén $N^{\circ} 6$

Casa Blanca $N^{\circ} 34$
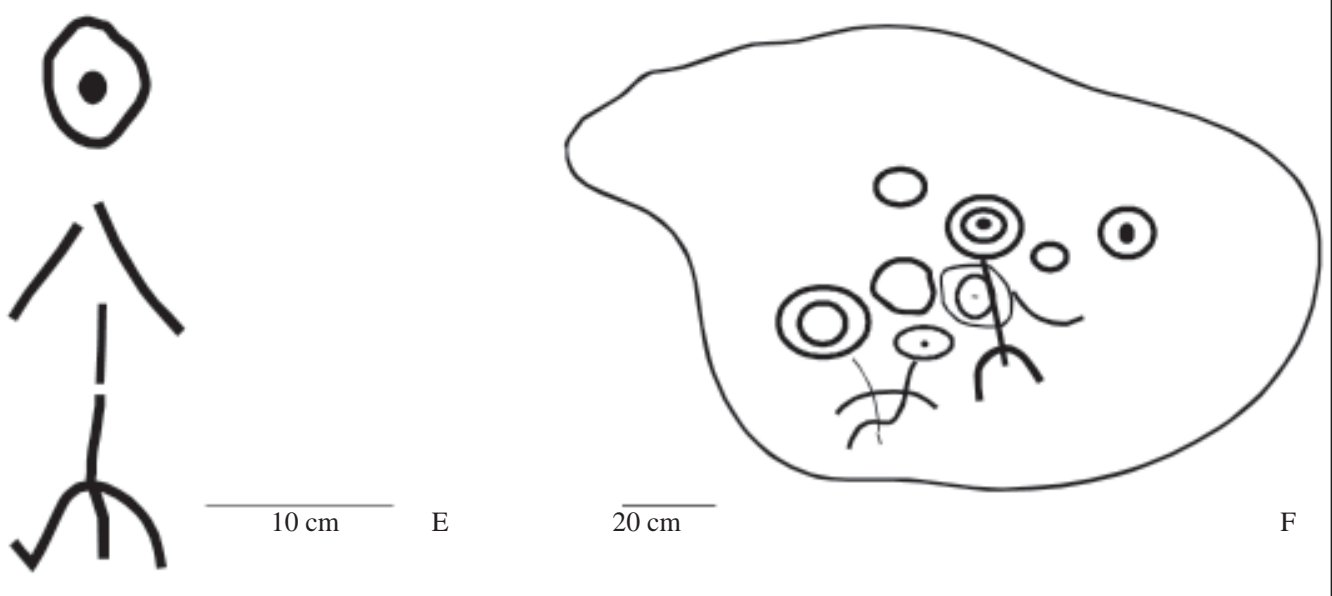

Figura 5. Figuras antropomorfas Estilo I.

Anthropomorphic figures, Style I. 


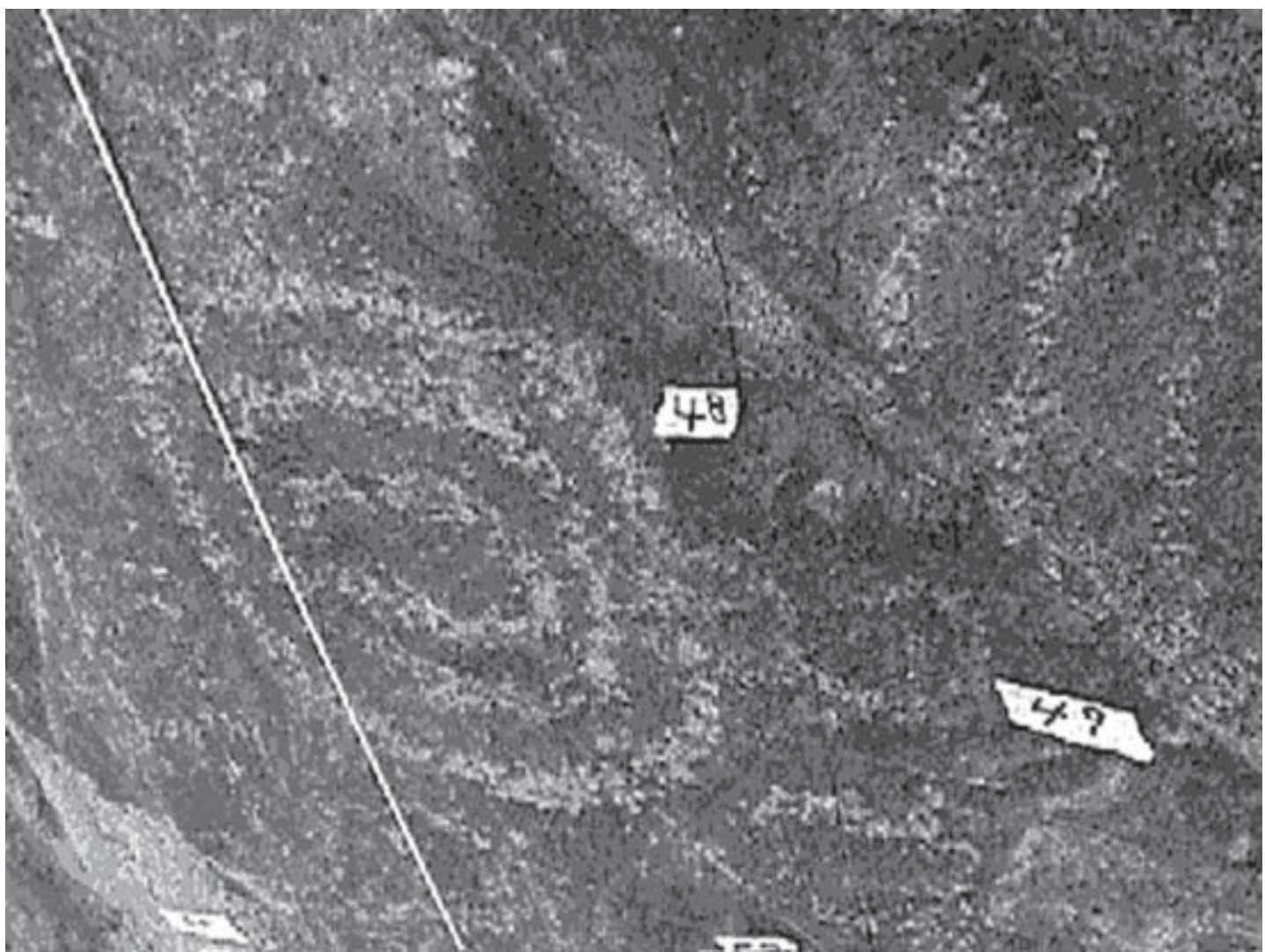

Figura 6. Cuadrado concéntrico superpuesto a círculos yuxtapuestos. Casa Blanca 14.

Concentric square, superimposed to juxtaposed circles. Site Casa Blanca 14.

gicamente en dos fases: una histórica temprana y otra histórica tardía. Estas definiciones de estilo son iniciales y necesitan una mayor elaboración en el futuro, básicamente porque algunas figuras registradas no pudieron ser adscritas a ninguno de los estilos debido a su baja representación. Asimismo, el estudio de las técnicas utilizadas en la producción de los grabados rupestres muestra una gran homogeneidad en los diferentes estilos, respondiendo todos a la técnica de piqueteado y raspado, así como manejando atributos métricos similares (tanto de tamaño como de grosor del surco).

\section{Estilo I (período Intermedio Tardío)}

Este estilo sería el mayormente representado en el área y correspondería al llamado estilo Aconcagua. Se caracterizaría por una amplia representatividad de figuras geométricas, una menor frecuencia de figuras humanas y ausencia de figuras zoomorfas ${ }^{6}$. El elemento figurativo básico y predominante, que caracteriza a este estilo, es la figura circular. Sin embargo, esta construcción se rige por unas normas de elaboración que se traducen en una amplia gama de motivos. La característica principal de la confección de la figura circular es que casi nunca se representa en forma simple. Por el contrario, en sus posibilidades decorativas se encuentra tanto la aplicación de apéndices y yuxtaposiciones (Figura 7d). En algunos casos se ha observado la aplicación de decoraciones interiores, trazos diagonales y horizontales formando figuras cuatripartitas, bipartitas y enrejadas, que si bien responden a un patrón circular, su baja representación, su ausencia de asociación espacial con paneles que presentan figuras del Estilo I y sus normas decorativas particulares, indican cierta diferencia con el modelo clásico del arte rupestre del período Intermedio Tardío.

Otra variedad decorativa del círculo es la creación de círculos concéntricos, simples o compuestos. Ambas variedades pueden presentar algún tipo 

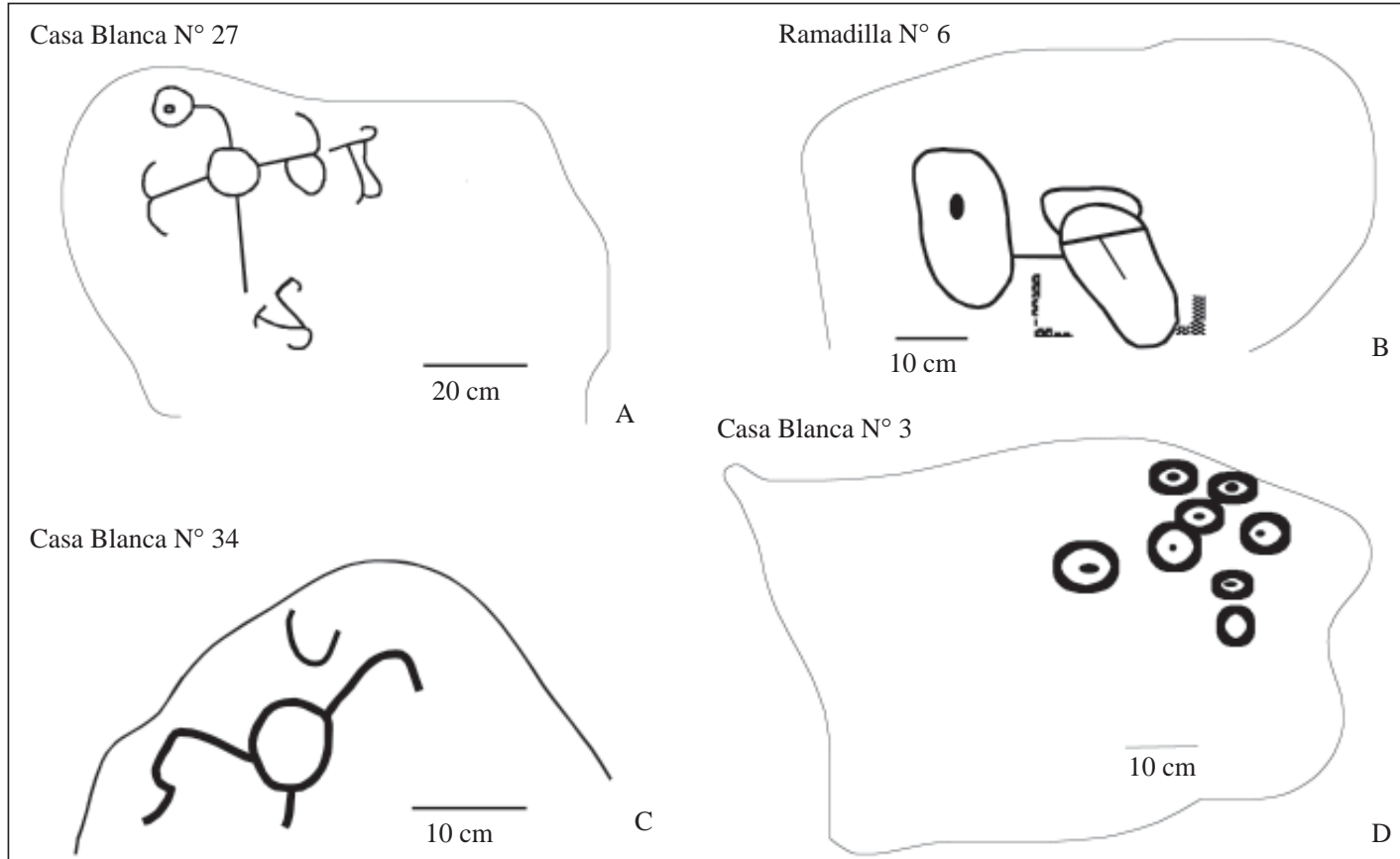

$A$

Casa Blanca $\mathrm{N}^{\circ} 3$

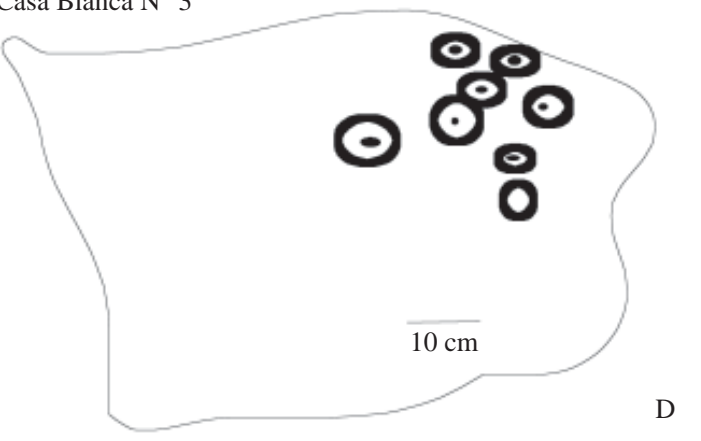

Casa Blanca $\mathrm{N}^{\circ} 2$

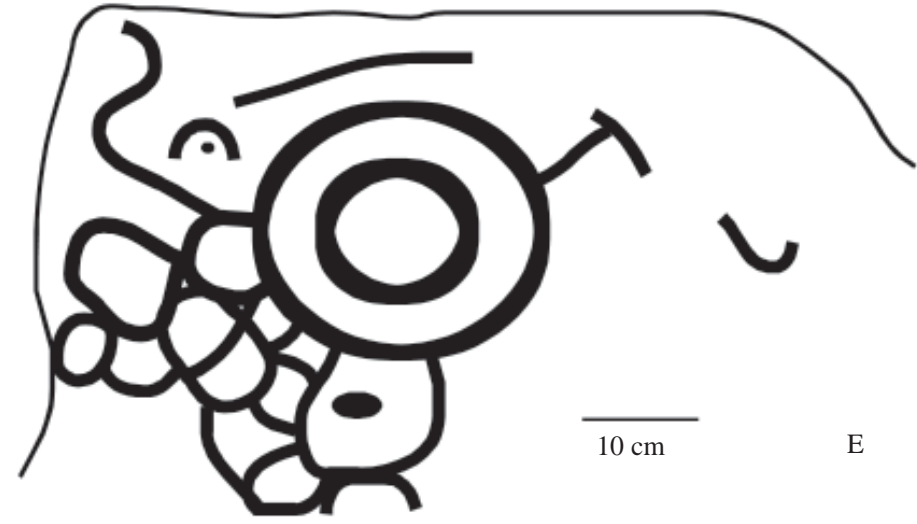

Figura 7. Figuras geométricas Estilo I.

Geometric figures, Style I.

de decoración interior, como un punto central o trazos lineales. Este elemento decorativo se aplica, sin embargo, al interior del círculo más pequeño y en ningún caso entre los diferentes círculos inscritos. Los apéndices lineales también forman parte de este universo de representación como elementos decorativos que generan figuras tipo sol y otros, pero ellos no se aplican a los círculos concéntricos compuestos (Figuras 7a, c y e).
A partir de la combinación de las estrategias decorativas mencionadas se genera gran parte de la representación rupestre de este estilo. A ello debe sumarse la yuxtaposición como herramienta constructiva de muchos motivos, originando algunas figuras como círculos agrupados (Figura 7e). La cantidad de figuras posibles de ser construidas a partir de la conjunción de todos estos elementos es inmensa y es ello lo que explica la gran variedad 
de imágenes rupestres que exhibe este estilo. Estas mismas estrategias de construcción del motivo hacen ver este arte como una expresión ambigua, donde la conjunción de reglas indica que un mismo elemento pueda ser en sí una figura y/o ser parte de un motivo mucho más amplio ${ }^{7}$.

La importancia del círculo en arte rupestre del valle de Putaendo se basa no tan sólo en su casi exclusiva representación en el ámbito geométrico, sino también porque actúa como elemento de construcción de la figura humana. Puede objetarse que es natural su presencia en los motivos antropomorfos por cuanto es un elemento lógico de representación de la cabeza; ello puede ser correcto o erróneo, pero lo que lo distingue es que el círculo representa, además de cabezas, también cuerpos y pelvis, todos ellos con algún tipo de decoración interior.

Con respecto a la figura humana, creemos que en principio es posible pensar que gran parte de ellas corresponde a este estilo, pues a pesar de su gran diversidad muchas comparten importantes elementos constructivos y se asocian espacialmente en los paneles con círculos. La diversidad presente en este tipo de figuras nos hace diferenciar en principio tres clases de representaciones antropomorfas, lo que confirma la amplia dispersión decorativa que caracteriza a este estilo de arte rupestre.

El primer tipo de figura humana correspondería a aquellas de carácter poco esquemático, dibujadas a partir del delineamiento de los diferentes sectores del cuerpo humano que guardan cierta proporcionalidad en sus dimensiones, a excepción de las extremidades superiores que, en la mayoría de los casos, son notoriamente largas en comparación al cuerpo. Sus extremidades están siempre presentes, y en algunos casos manos y pies se dibujan. Los detalles mínimos del cuerpo, como ojos, boca, nariz, etc., no son representados (Figuras 5a, c-f). La representación humana siempre se realiza de frente y mayoritariamente en una posición de pie. Las figuras presentan una animación nula, básicamente del tipo oblicua. No obstante este tipo de animación, es importante la representación de ángulos en brazos y piernas, dando la idea de algún tipo de acción-expresión (Figuras $5 \mathrm{c}$ y d). Tocados y otros atributos decorativos se presentan en estas figuras sin que de momento pueda ser posible adentrarse mayormente en sus asociaciones significativas (Figura 5c).
Figuras antropomorfas algo más esquemáticas han sido incluidas dentro del segundo grupo de estos motivos. A diferencia del caso anterior, estas representaciones humanas basan su construcción en la aplicación de círculos concéntricos simples, como unidad básica a partir de la cual se construye la figura humana. Aunque en la gran mayoría de los casos los círculos se aplican en la cabeza, también están presentes a nivel del tronco y pelvis. Generalmente estos círculos presentan una decoración interior de puntos (Figuras 5d-f,). Como en el caso anterior, la animación entre estas figuras es nula, encontrándose todas de pie. La geometría de la representación de estas figuras impidió una efectiva aplicación de la ficha de relevamiento para figuras antropomorfas.

Un tercer grupo de figuras humanas se conforma a partir de la aplicación de elementos lineales, que Niemeyer (1964) denominara "antropomorfas fitomorfizadas". Se caracterizan por presentar una serie de extremidades, a manera de apéndices lineales, adosados a su tronco en números que no necesariamente guardan relación con la realidad, es decir, dos pares de extremidades. Estas características sumadas, en algunos casos, a su esquematización, hacen posible cuestionar su asignación como figuras realmente humanas. Es posible pensar también en zoomorfos esquematizados y/o figuras del mundo ideacional (Figura $5 b$ ).

Encontramos por tanto, en este estilo de arte rupestre, una amplia variabilidad en lo que a la expresión de la figura humana se refiere. No obstante esta variedad, existe coincidencia en representar al ser humano siempre en un estado de animación nula y con un gran tamaño en sus extremidades superiores. Gran parte de las figuras comparte un rango de tamaño en sus proporciones (largo medio $=12,8$ $\mathrm{cm}$; ancho medio $=11,6 \mathrm{~cm}$ ). La tecnología para la elaboración de todas las figuras ha sido el piqueteado y raspado de la piedra por otro instrumento lítico.

Espacialmente, este arte rupestre se caracteriza por no presentarse en asociación con los sitios habitacionales contemporáneos. Frecuentemente no tienen ningún tipo de material cultural en asociación, aunque en ocasiones se relaciona espacialmente a sitios del período Histórico. Una excepción la constituyen los petroglifos localizados al interior de la rinconada de Piguchén (sitios 2, 3, 5 y 6), donde los paneles se encuentran junto a sitios del período Alfarero Temprano. Este hecho 
podría hacer pensar que este arte rupestre habría que asignarlo a este período, pero la regularidad observada nos permite sugerir que la asociación de Piguchén fue el resultado "aleatorio" del proceso de formación del registro arqueológico local ${ }^{8}$.

La principal razón que fundamenta su asociación al período Intermedio Tardío es por el hecho que se ubica preferentemente en los mismos espacios donde encontramos sitios correspondientes a ese período. Sugerente, en este sentido, es la ausencia de paneles de petroglifos en rinconadas aptas para el asentamiento humano donde no se ha localizado ningún sitio habitacional de este período. Niemeyer (1964), y posteriormente Mostny y Niemeyer (1983), asociaron este arte rupestre al período Intermedio Tardío debido a las características geométricas de los diseños observadas también en la cerámica. Creemos que esta idea es aún válida para mantenerla como identificador de asociación cronocultural; sin embargo, las investigaciones efectuadas en el valle de Putaendo, y otros sectores del curso superior del río Aconcagua, han mostrado la existencia de un contexto arqueológico muy diferente al manejado para la época en que formularon sus proposiciones Mostny y Niemeyer (1983). En tal sentido, las características de la decoración cerámica no guardan ninguna relación con los elementos decorativos del arte rupestre, salvo su énfasis en lo geométrico. Este hecho, que en principio podría preocupar, creemos que debe ser matizado pues las semejanzas pueden estar en aspectos de mayor profundidad (estructuras), situación que sumada a la ausencia de otros artefactos con atributos decorativos nos impiden conocer la variedad iconográfica de este período, así como su diferenciación en términos de la materialidad sobre la que se aplica. Además, y aunque es siempre esperable una correlación entre iconografía de los diferentes ámbitos de la vida material de las poblaciones humanas, su diferente aplicación en la materialidad misma es siempre una posibilidad abierta, aún más cuando entendemos que "la materialidad desempeña en el papel un enunciado mucho más importante. Constituye el enunciado mismo" (Foucault 1997[1970]:169).

Por los resultados de las investigaciones arqueológicas, sugerimos eliminar el nombre de estilo Aconcagua para esta forma de arte rupestre con el fin de evitar asociaciones no intencionadas entre esta cultura y este estilo. Esta cultura no se encuentra en la cuenca superior del río Aconcagua
(Sánchez 2000a, 2000b), principal zona de dispersión de este arte rupestre. Por esta razón, la relación sugerida no puede ser sostenida y el mantenimiento del nombre estilo Aconcagua puede conducir a malentendidos. Consecuentemente, sugerimos denominar a este conjunto como Estilo I de arte rupestre de Putaendo.

Podrá objetarse como contraevidencia de esta asociación la presencia de este tipo de arte rupestre en la precordillera y cordillera del río Maipo, territorio con clara presencia de la cultura Aconcagua (Madrid 1969, Miranda y Saavedra 1997). Sin embargo, el registro arqueológico no avala en ninguna medida esta asociación, ya que, por un lado, los desarrollos prehispánicos son bastante diferentes en nuestra zona de estudio y el valle del Maipo, y, por otro, las frecuencias de arte rupestre son opuestas en ambos sectores, con una alta representatividad en el primero y una escasa presencia en el segundo (ver comentario de Sanguinetti [1969]) relativo a la semejanza del arte rupestre de esta zona con su símil de Alicahue y Cabildo). Este hecho sería coherente con las características que presenta el registro arqueológico local desde a lo menos el período Alfarero Temprano, donde se observa una mayor relación con los desarrollos culturales de zonas más nortinas que con los de Chile central.

Finalmente, creemos conveniente afirmar que el signo escudo no es la figura que mejor representa a este estilo, sino que, por el contrario, el motivo básico de este arte rupestre es el círculo, idea que ya había sido avanzada por Sanguinetti (1968). La alta frecuencia de signos escudos en otras zonas de la cuenca superior del río Aconcagua debe entenderse inicialmente, como una consecuencia de la variabilidad espacial dentro del registro de la zona. Esta variación puede dar cuenta de diferencias dentro de la dinámica social del área, o de diferencias cronológicas entre las distintas representaciones rupestres del valle de Aconcagua.

\section{Estilo II (período Tardío o Inca)}

El segundo estilo de arte rupestre que se propone para el valle de Putaendo, y por ende para el curso superior del río Aconcagua, es de tiempos incaicos y se fundamenta en los datos que se han recuperado a partir del descubrimiento del pucara El Tártaro y los atributos constructivos de ciertos motivos registrados en nuestro estudio. Sin embar- 
go, este estilo se encuentra en una etapa inicial de definición, por lo que su presentación no está tan sistematizada como el Estilo I.

El primer elemento que permite definir este estilo es la existencia de una superposición identificada en un panel adyacente al sitio pucara El Tártaro. En esta superposición se identifica la presencia de un motivo lineal de trazo fino, posiblemente elaborado con un instrumento metálico, sobre una figura de surco grueso asignable al Estilo I (Figura $8 b)$. Un segundo elemento de juicio es el registro de una serie de paneles en el cordón montañoso en el que se emplaza el pucara. Tanto la asociación espacial con este sitio como las características de sus motivos sugieren una asociación contextual con lo Inca (Figuras 8a y 9).

Este estilo se caracterizaría por una importante presencia de figuras lineales, la reformulación de algunos motivos del Estilo I y la posible continuación de diseños anteriores. Para el primer caso, el registro en el sitio pucara El Tártaro muestra elementos lineales aleatoriamente distribuidos en el panel. Es posible que forme también parte de este contexto lineal la figura de una cruz inscrita. Aunque este motivo se ha asociado clásicamente al Estilo I, es significativo el hecho que un diseño similar está presente en cerámica del período Tardío en el curso superior del río Aconcagua. Además, un panel próximo al pucara exhibe un número importante de estas figuras, no registradas mayormente en el valle. Asimismo, dentro de las reglas estructurantes que definen el primer estilo se observa una total ausencia de figuras lineales inscritas (Figuras 8a y e). Coherente con lo anterior, creemos que dos figuras a manera de "I" latina mayúscula inscritas, registradas en el sitio C.B. 14, forman parte de este estilo.

Dentro de la geometría de este arte también encontramos la figura cuadrangular. Un cuadrilátero de lados curvos se encuentra en el pucara con el mismo surco delgado ya mencionado (Figura 8b). Es sugerente que el registro de un motivo muy similar a este se encuentra en el sitio C.B. 33, donde junto con elementos decorativos del Estilo I también se encuentran figuras de difícil adscripción y otras de tiempos históricos (Figura 4). Otro elemento cuadrangular corresponde al cuadrado concéntrico existente en C.B. 14, que se superpone a una figura circular (Figura 6). Esta superposición no tiene ninguna lógica de reutilización del referente para construir un nuevo motivo, sino que por el contrario es completamente disruptiva. Se suma, además, el carácter concéntrico en el Estilo I propio de los círculos, rasgos ausente entre los cuadrados, que a su vez poseen una baja representación en el total de figuras.

Se refuerza la anterior idea al revisar la iconografía plasmada por Guaman Poma (1987), en la cual no sólo abundan las decoraciones cuadrangulares en las vestimentas incaicas, sino que en especial el cuadrado concéntrico presenta una alta frecuencia de representación tanto en vestimentas como en escudos (Figuras 10 y 11). Si bien el grabado rupestre y la ilustración del cronista están distanciados temporalmente y las figuras mencionadas se insertan en contextos representacionales diferentes, lo interesante de este hecho es que ambas figuras comparten un código de producción formal similar, cual es la aparición de un elemento cuadrado con una decoración orientada hacia el interior, compartiendo por ello una lógica representacional, que en este caso es significativa, ya que como ha indicado Adorno (1981) las producciones visuales del cronista peruano se ajustan a un código estético incaico antes que hispánico. Los elementos circulares se mantienen durante ese momento, y aunque sufren algunas modificaciones, es posible que muchas figuras se mantuvieron en el tiempo. Una figura que recibe una clara modificación es el círculo concéntrico compuesto, el cual adquiere una decoración lineal interior, que se ubica entre los diferentes radios de los círculos inscritos y no en el vacío generado por el círculo menor (Figura 8a). Círculos concéntricos simples y círculos cuatripartitos están también presentes en este arte del valle. Las características formales de los signos escudos, su ausencia de asociación espacial en paneles con figuras propias del Estilo I y el registro de estas figuras en un panel ubicado a la entrada del pucara El Tártaro siembra la duda sobre su asociación al período Intermedio Tardío (Figura 8d).

La representación de la figura humana es aún poco clara en este estilo, sin embargo, creemos posible asignar un par de figuras humanas muy particulares registradas en el sitio C.B. 14. Aunque ellas comparten algunos rasgos de otros seres humanos, se diferencian por la existencia de ojos, una casi total ausencia representativa de la cabeza (un trazo a manera de gran ceja) y una desmesurada representación del tronco a partir de círculos concéntricos a los que se añaden apéndices a ma- 


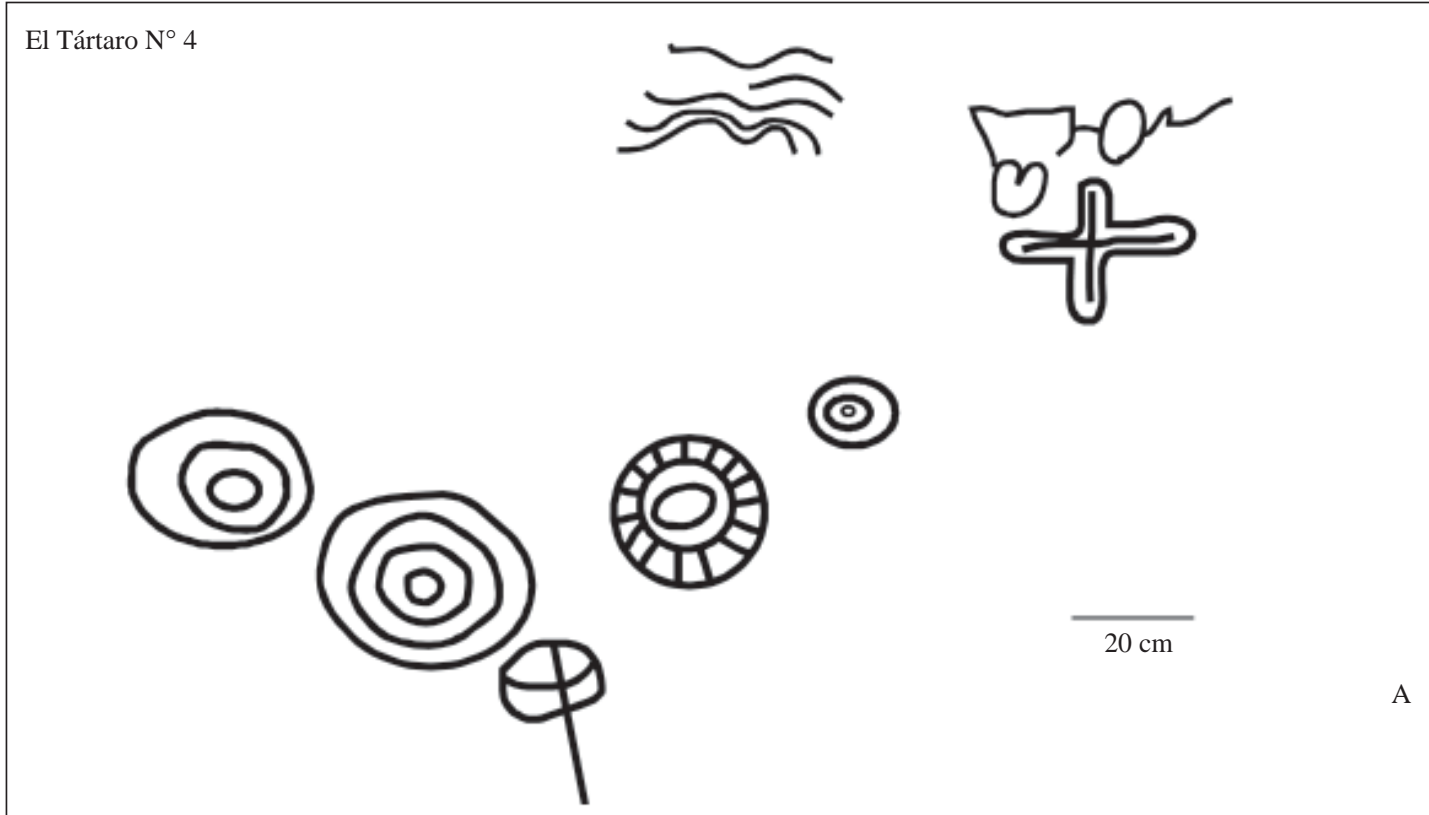

El Tártaro $\mathrm{N}^{\circ} 1$
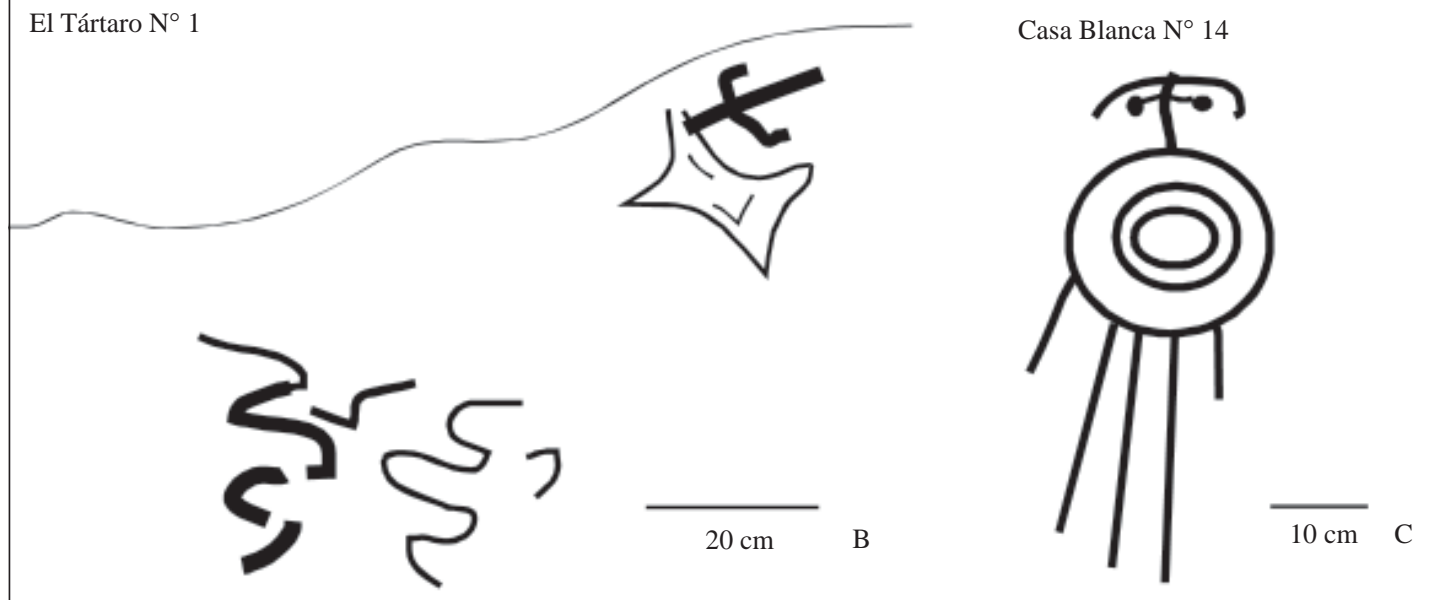

El Tártaro $\mathrm{N}^{\circ} 5$

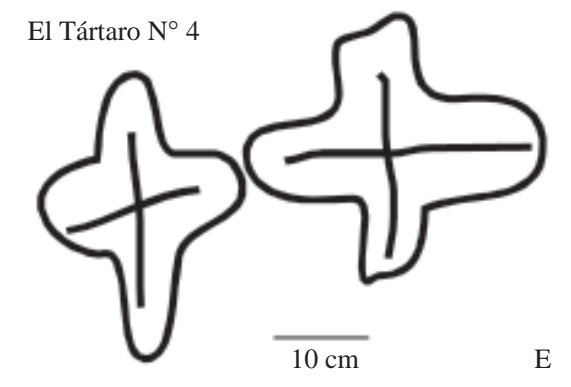

Figura 8. Figuras geométricas y antropomorfas Estilo II.

Geometric and anthropomorphic figures, Style II. 


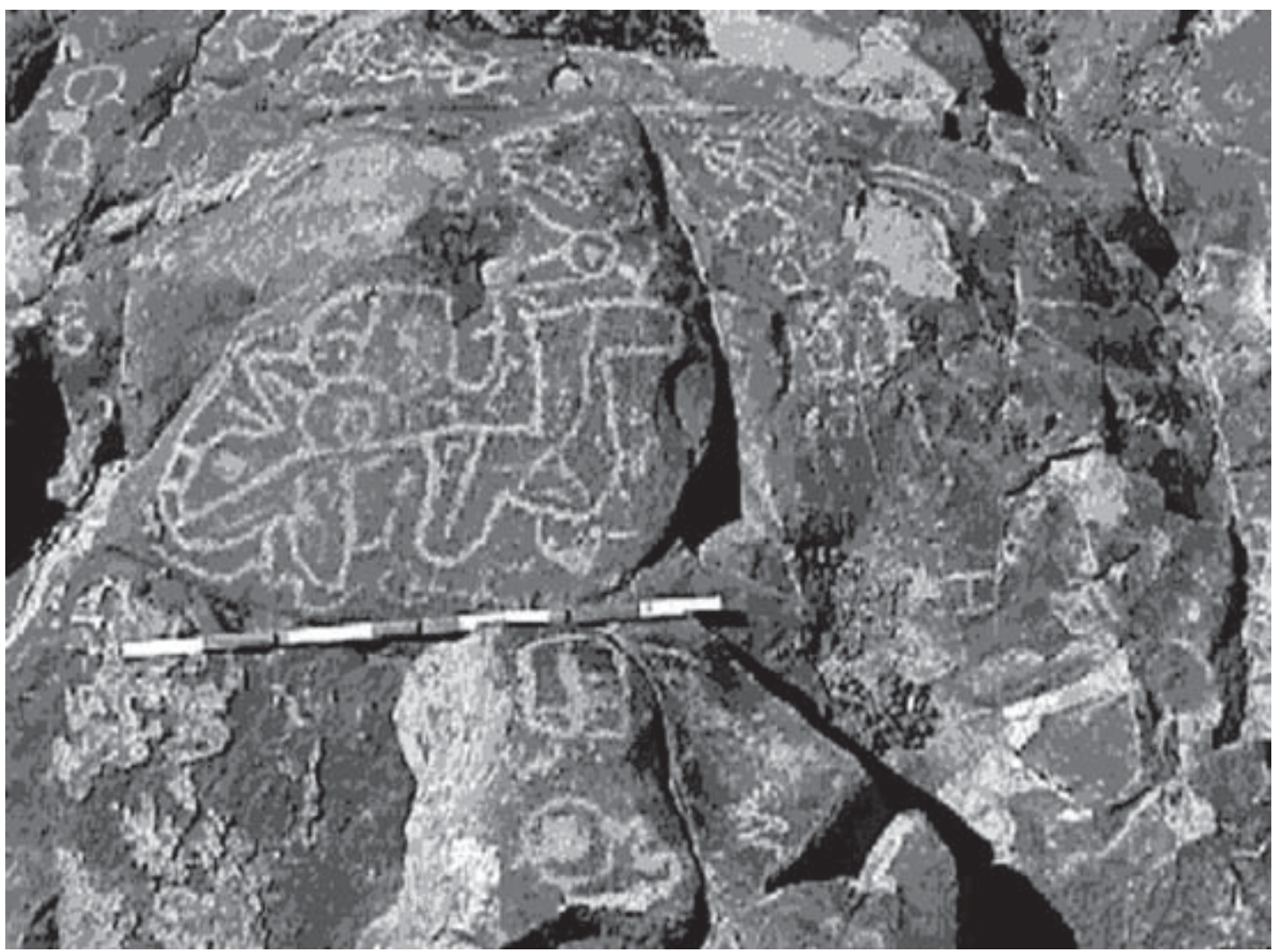

Figura 9. Figura zoomorfa inscrita y motivos asociados. Sitio El Tártaro 3.

Incised zoomorphic figures and associated motifs. Site El Tártaro 3.

nera de extremidades ${ }^{9}$. Su animación es nula y están de pie y de frente (Figura 8c). Figuras zoomorfas no se registran.

Todos los elementos diferenciales que se han expuesto previamente permiten aseverar la existencia de una serie de figuras rupestres que: (i) poseen elementos constructivos de diseño diferentes al Estilo I; (ii) algunos de estos elementos figurativos estarían referenciados en la cerámica del período Incaico, y (iii) tienen una distribución espacial en el sitio del pucara El Tártaro, sus cercanías y en la principal estación de arte rupestre del valle de Putaendo, C.B. 14. Por estas razones, consideramos que estamos frente a un conjunto de figuras diferenciadas del Estilo I, que de momento pueden agruparse en un Estilo II asociado a tiempos incaicos. Aunque el número de figuras registradas no es muy alto, consideramos significativo el hecho de diferenciarse de aquellas propias del Estilo I de arte rupestre. Esto sugiere una materialización según reglas y lógicas de producción discursiva di- ferentes, por lo que este Estilo II de arte rupestre da cuenta de formas y contenidos diferentes a los del primer estilo.

\section{Estilo III (período Histórico)}

Más que corresponder a un estilo tal cual lo hemos definido en este estudio, nos encontramos más bien ante representaciones de un estilo, pues su baja incidencia hace imposible definirlo a partir de su normativa constructiva. En principio, esta forma de arte puede ser subdividida en dos grupos: uno correspondiente a tiempos históricos tempranos y otro a épocas históricas tardías.

El primer caso se ejemplifica solamente en el sitio C.B. 33 a partir de una escena de monta representada por un ser humano y un cuadrúpedo. La construcción de los motivos es de tecnología similar a la de las figuras prehispánicas, es decir, un grueso surco efectuado por piqueteado y raspado. La figura humana carece de cuerpo y tiene unos 


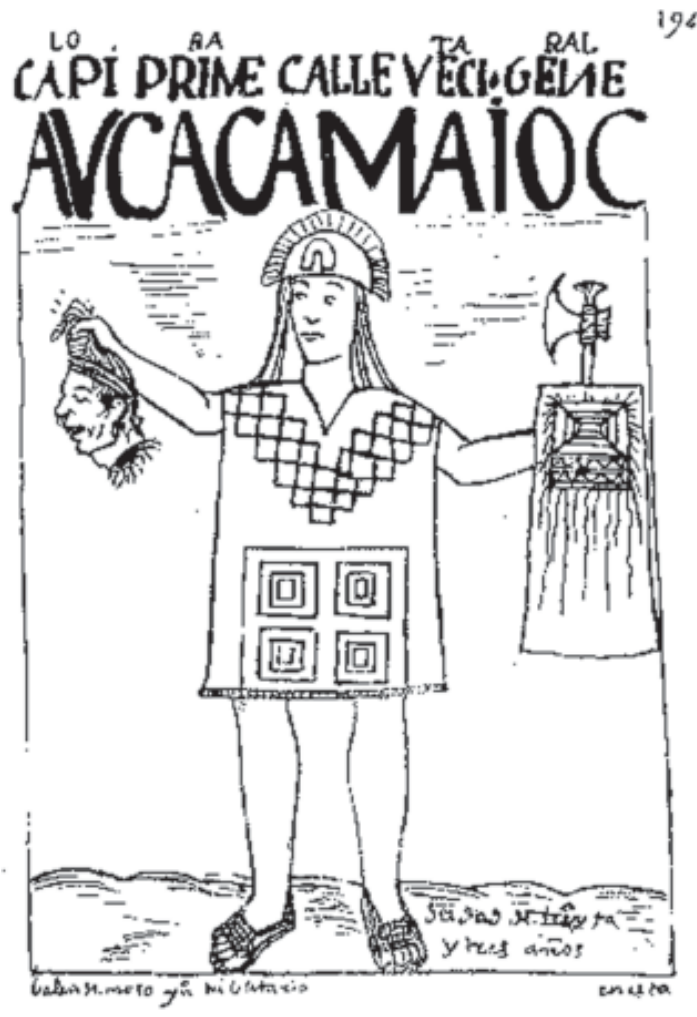

Figura 10. Cuadrados concéntricos dibujados por Guaman Poma en vestimentas incaicas.

Concentric squares in Inca clothing drawn by Guaman Poma.

largos brazos, el cuadrúpedo por su parte está representado por una construcción lineal de extremidades y orejas. Asociada a esta figura se encuentra otra figura humana con una representación lineal, donde la cabeza se muestra como un punto y brazos extremadamente largos con indicación de las manos (Figura 12). Esta expresión artística se asigna al período Histórico Temprano debido a que las características tecnológicas del petroglifo se asemejan a sus pares prehispánicos, por lo que posiblemente fue elaborado por manos indígenas. El arte Histórico Tardío abarca todos aquellos grabados elaborados por manos no indígenas y que exhiben básicamente cruces cristianas.

\section{Conclusiones}

Las diferentes formas de arte rupestre propuestas deben ser entendidas como entidades abiertas a modificaciones que basan su definición en los resultados de investigaciones realizadas en el valle de Putaendo, por lo que es esperable que éstas no

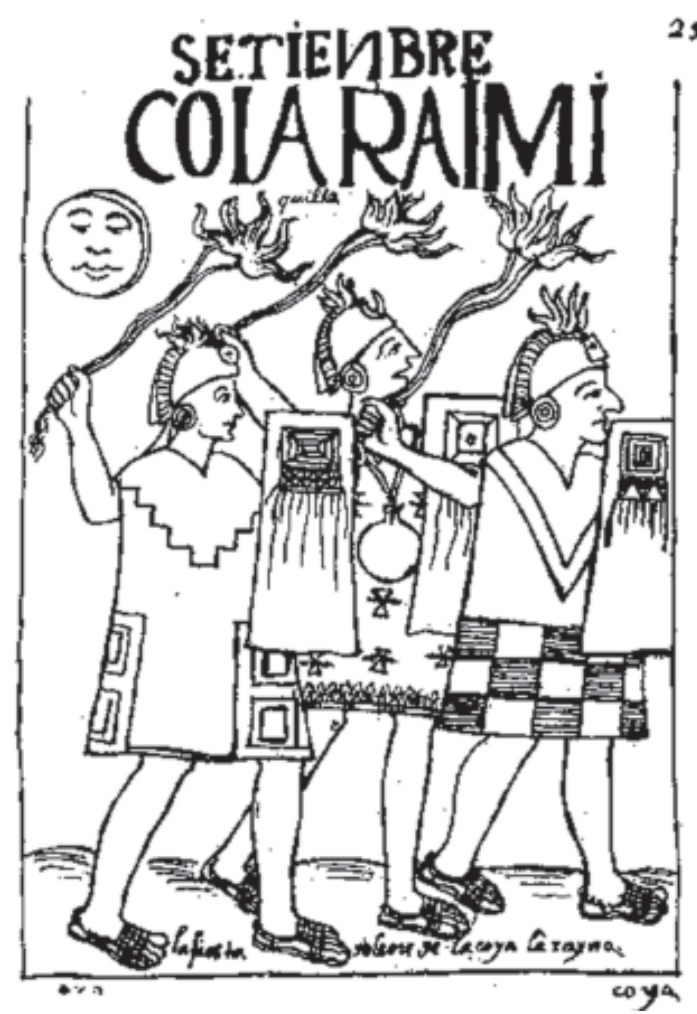

Figura 11. Cuadrados concéntricos dibujados por Guaman Poma en escudos incaicos.

Concentric squares of Inca shields drawn by Guaman Poma.

agoten la definición de otros estilos en el curso superior del río Aconcagua. Se presentan, sin embargo, como punto de partida acerca de las diferentes formas de arte rupestre que se encuentran en la historia indígena del área.

En nuestro caso, es el Estilo I el que presenta la más clara definición, debido básicamente al tamaño de la muestra estudiada, sin embargo, nuevos datos deben ser incluidos con el fin de ampliar el área de estudio. El Estilo II, por su parte, se encuentra en un estado inicial de definición y requiere de una muestra mayor de estudio para esbozar los elementos que delinean su contenido. En el estado actual de la investigación, se define como un conjunto de figuras que se asocia más con lo inca que a un estilo propiamente tal. En el futuro se deberá aclarar si las diferentes expresiones artísticas de este tiempo se ciñen a un conjunto de principios estilísticos similares, y si las materialidades reflejan cambios socioculturales de este período. Similar hecho deberá verificarse con el arte de tiempos históricos. 


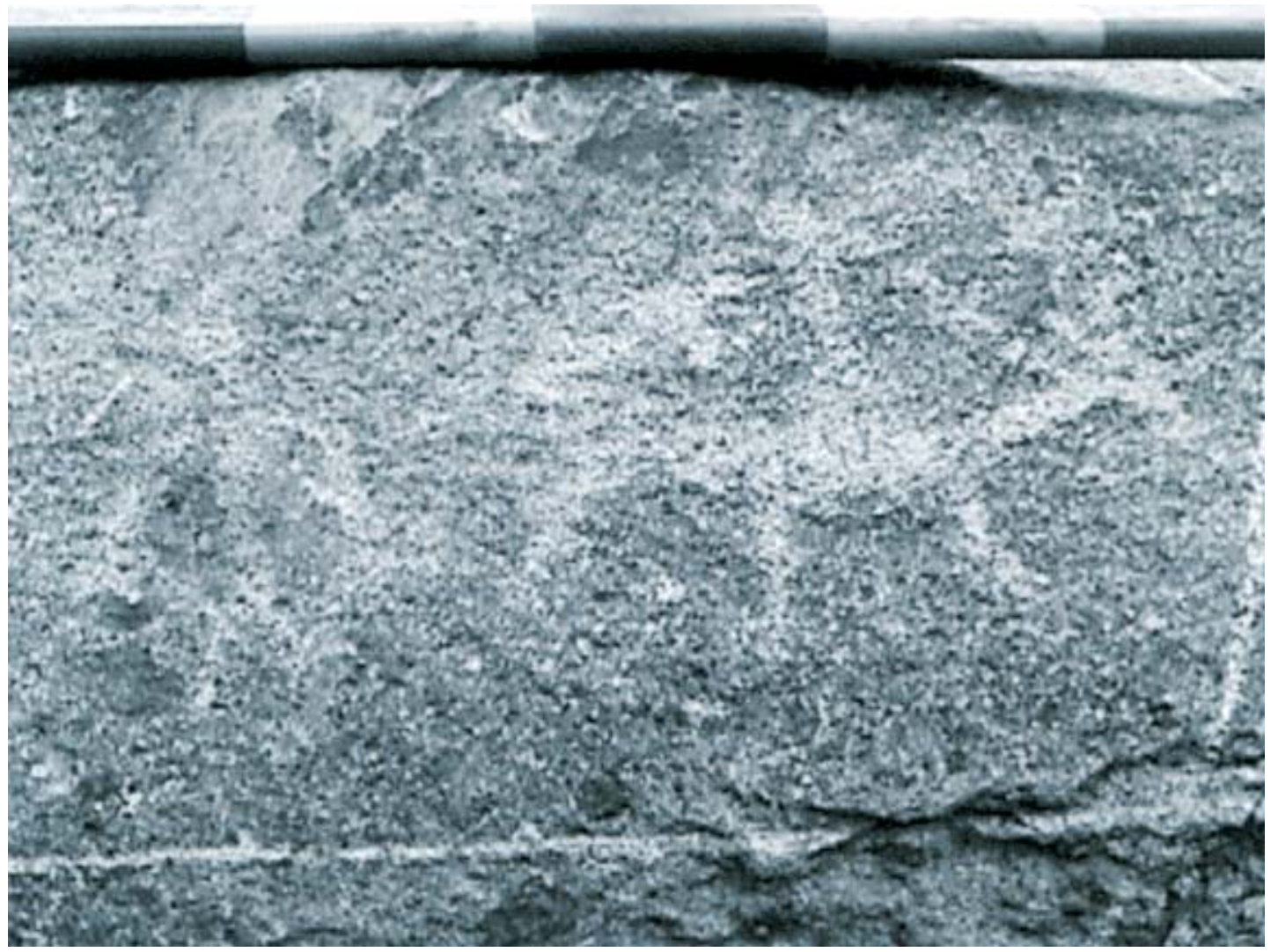

Figura 12. Escena de monta. Sitio Casa Blanca 33.

Horseback riding scene. Site Casa Blanca 33.

Esta proposición de estilos de arte rupestre no se debilita por lo anteriormente dicho; ilusorio sería postular desde nuestra perspectiva tres estilos en forma cerrada y definitiva con una muestra tan pequeña de estudio, más aún teniendo en cuenta que esta investigación, en curso, está orientada específicamente al arte rupestre de la zona. Estos tres estilos son guías ordenadoras iniciales que esperamos complementar en el futuro y que de momento permiten revitalizar el estudio del arte rupestre del curso superior del río Aconcagua. El siguiente paso es ampliar nuestra mirada y comparar los principios que guían la producción de las imágenes rupestres con aquellas provenientes de otros soportes materiales.
Agradecimientos: Esta proposición no habría sido posible sin la ayuda de mi amigo Rodrigo Sánchez, investigador responsable del proyecto Fondecyt 1970531 y de los amigos Daniel Pavlovic, investigador responsable del Proyecto Fondecyt $\mathrm{N}^{\mathrm{o}}$ 1000172, e Ismael Martínez, quienes en forma angustiosa debieron soportar interminables días con sólo círculos, puntos y líneas en sus ojos y mentes. Asimismo, comprometen inmensamente mi gratitud Francisco Gallardo y Claudia Silva por toda la ayuda metodológica prestada y por todo lo dado, así como los dos evaluadores del presente trabajo que contribuyeron enormemente a la mejora del mismo con sus acertados comentarios y reflexiones.

\section{Referencias Citadas}

Adorno, R.

1981 On pictorial language and the tipology of culture in a new world chronicle. Semiotica 36:51-106.
Conkey, M. y C. Hastorf, editores

1993 The Uses of Style in Archaeology. Cambridge University Press, Cambridge. 
Clarke, D.

1986 [1968] Arqueología Analítica. Ediciones Bellatera, Barcelona.

Criado, F.

1999 Del Terreno al Espacio: Planteamientos y Perspectivas para la Arqueología del Paisaje. CAPA 6, Santiago de Compostela.

Foucault, M.

1991 [1968] La función política del intelectual. En Saber y Verdad, compilación de M. Foucault, pp. 47-74. Ediciones de La Piqueta, Madrid.

1992 Microfísica del Poder. Ediciones de La Piqueta, Barcelona.

1997 [1970] La Arqueología del Saber. Siglo XXI editores, Madrid.

Gallardo, F., F. Vilches, L. Cornejo y C. Rees

1996 Sobre un estilo de arte rupestre en la cuenca del río Salado (norte de Chile): un estudio preliminar. Chungara 28:353-364.

Guaman Poma de Ayala, F.

1987 Nueva Crónica y Buen Gobierno. Colección Historia 16, Siglo XXI Editores, Madrid.

Igualt, $\mathrm{F}$

1970 Investigación de petroglifos en Jahuel. Anales del Museo Historia Natural de Valparaíso 3:193-202.

Kroeber, A.

1969 [1957] El Estilo y la Evolución de la Cultura. Ediciones Guadarrama, México.

Madrid, J.

1969 Petroglifos del cerro Los Ratones, Cajón del Maipo, Prov. de Santiago. Actas del V Congreso Nacional de Arqueología, pp: 277-294, La Serena.

Miranda, P. y M. Saavedra

1997 Arte rupestre en el río Colorado, Cajón del Maipo. Boletín de la Sociedad Chilena de Arqueología 24:18-19.

Morphy, $\mathrm{H}$.

1994 The anthropology of art. En Companion Encyclopedia of Anthropology, editado por T. Ingold, pp. 648-685. Routledge, Londres.
Mostny, G. y H. Niemeyer

1983 Arte Rupestre Chileno. Ministerio de Educación, Serie Patrimonio Cultural Chileno, Santiago.

Niemeyer, $\mathrm{H}$.

1964 Petroglifos en el curso superior del río Aconcagua. Arqueología de Chile Central y Áreas Vecinas, Actas del III Congreso Internacional de Arqueología Chilena, pp. 133150, Viña del Mar.

Panofsky, E.

2000 [1995] Tres Ensayos Sobre el Estilo. Editorial Paidós, Barcelona.

Pavlovic, D.

2000 Período Alfarero Temprano en la cuenca superior del río Aconcagua: una primera aproximación sistemática a sus características y relaciones. Boletín de la Sociedad Chilena de Arqueología 30:17-29.

Pavlovic, D., R. Sánchez y A. Troncoso

2002 Prehistoria de Aconcagua. Ediciones del Centro de Artes y Oficios El Almendral, San Felipe.

Sánchez, R.

2000a Nuevas investigaciones en el curso superior del río Aconcagua, su repercusión para la prehistoria de Chile central. Actas del III Congreso Chileno de Antropología Vol. I: 423-429. Lom Editores, Santiago.

2000b Cultura Aconcagua en el valle del río Aconcagua, una discusión sobre su cronología e hipótesis de organización dual. Actas del XIV Congreso Nacional de Arqueología Chilena Vol. II: 147-160. Contribución Arqueológica 5, Museo Regional de Copiapó.

Sanguinetti, N.

1968 Algunos petroglifos de Piguchén. Anales del Museo de Historia Natural de Valparaíso 1:249-259.

1969 Un petroglifo de Hierro Viejo. Anales del Museo de Historia Natural de Valparaíso 1:225-236.

Santos, M.

1997 Los espacios del arte: el diseño del panel y la articulación del paisaje en el arte rupestre gallego. Trabajos de Prehistoria 55:73-88.

Troncoso, A.

1998 Petroglifos, agua y visibilidad: el arte rupestre y la apropiación del espacio en el curso superior del río Putaendo, Chile. Valles 4:127-137.

\section{Notas}

$1 \quad$ Clarke (1986 [1968]: 443) señaló que "un agregado de entidades o sistema es politético si cada individuo posee un número sin especificar de los atributos del agregado, si cada atributo pertenece a un gran número de esos individuos y ningún simple atributo es a la vez necesario para el agregado".

2 La potencialidad de este texto de Foucault (1997 [1970]:53) para el análisis del arte rupestre puede deparar una gran rentabilidad, pues define un positivo acercamiento a una expresión del saber y, si se desea, se puede avanzar desde ella hasta los contornos de los sistemas de saber-poder prehispánicos.

3 Las normas regulatorias de la construcción del panel hacen referencia a una serie de convenciones sociales que definen desde la forma en que los motivos se articulan al interior del panel hasta la manera en que este debe ser observado. En este último punto véase por ejemplo Santos (1998).
4 Para efectos de análisis hemos discriminado entre círculo concéntrico simple correspondiente a aquella figura circular con sólo un círculo inscrito y círculo concéntrico compuesto, consistente en una figura circular con más de un círculo inscrito.

5 Prospecciones realizadas en la zona de Piguchén han permitido descubrir nuevos paneles de arte rupestre, representándose en dos de ellos posibles figuras zoomorfas de cuadrúpedos. El mal estado de conservación de las imágenes impide un mayor pronunciamiento de momento.

6 La ausencia de figuras zoomorfas ha sido ampliamente reconocida para este estilo. No obstante, en algunos casos una ínfima presencia de camélidos se ha registrado (Mostny y Niemeyer 1983).

7 Obviamente, esta ambigüedad parte de la incompatibilidad cultural existente entre el indígena-autor y el arqueó- 
logo-interpretador. El reconocimiento de este hecho, por ende, nos limita la búsqueda de significados en el registro arqueológico.

8 Usamos la palabra aleatorio de forma provisional y entre comillas, ya que no debe olvidarse que el emplazamiento de los petroglifos responde a una cierta lógica cultural guiada por un concepto particular de espacio, por lo que es posible que esta asociación con sitios Tempranos no sea casual, sino que por el contrario responda a una determinada estrategia de abordar el paisaje. De momento, y a falta de investigaciones al respecto, preferimos usar el término aleatorio.

9 Recuérdese que en el Estilo I las figuras humanas se construyen a partir de círculos concéntricos simples. 
